Portland State University

PDXScholar

Civil and Environmental Engineering Faculty

Publications and Presentations

Civil and Environmental Engineering

$12-31-2016$

\title{
A Validated Tropical-Extratropical Flood Hazard Assessment for New York Harbor
}

Philip M. Orton

Stevens Institute of Technology

T. M. Hall

NASA Goddard Institute for Space Studies

Stefan A. Talke

Portland State University, talke@pdx.edu

Alan F. Blumberg

Stevens Institute of Technology

Nickitas Georgas

Stevens Institute of Technology

See next page for additional authors

Follow this and additional works at: https://pdxscholar.library.pdx.edu/cengin_fac

Part of the Civil Engineering Commons, Environmental Engineering Commons, and the Hydraulic Engineering Commons

Let us know how access to this document benefits you.

\section{Citation Details}

Orton, P. M., T. M. Hall, S. A. Talke, A. F. Blumberg, N. Georgas, and S. Vinogradov (2016), A validated tropical-extratropical flood hazard assessment for New York Harbor, J. Geophys. Res. Oceans, 121, 8904-8929.

This Article is brought to you for free and open access. It has been accepted for inclusion in Civil and Environmental Engineering Faculty Publications and Presentations by an authorized administrator of PDXScholar. Please contact us if we can make this document more accessible: pdxscholar@pdx.edu. 
Authors

Philip M. Orton, T. M. Hall, Stefan A. Talke, Alan F. Blumberg, Nickitas Georgas, and S. Vinogradov 


\section{Journal of Geophysical Research: Oceans}

\section{RESEARCH ARTICLE \\ 10.1002/2016JC011679 \\ A validated tropical-extratropical flood hazard assessment for New York Harbor}

Key Points:

- A new approach for coastal flood hazard assessment is presented using synthetic tropical cyclones - The return period for Hurricane Sandy's flood is 260 years; it was the largest back to at least 1700 - Differing flood exceedance curves for extratropical and tropical cyclones require separate analysis

Correspondence to:

P. M. Orton,

philip.orton@stevens.edu

Citation:

Orton, P. M., T. M. Hall, S. A. Talke, A. F. Blumberg, N. Georgas, and S. Vinogradov (2016), A validated tropical-extratropical flood hazard assessment for New York Harbor, J. Geophys. Res. Oceans, 121, doi:10.1002/2016JC011679.

Received 25 JAN 2016 Accepted 21 OCT 2016 Accepted article online 25 OCT 2016

(c) 2016. American Geophysical Union. All Rights Reserved.

\author{
P. M. Orton'1, T. M. Hall2, S. A. Talke ${ }^{3}$ A. F. Blumberg1 , N. Georgas1, and S. Vinogradov ${ }^{1,4}$ \\ ${ }^{1}$ Davidson Laboratory, Stevens Institute of Technology, Hoboken, New Jersey, USA, ${ }^{2}$ NASA Goddard Institute for Space \\ Studies, New York, New York, USA, ${ }^{3}$ Department of Civil and Environmental Engineering, Portland State University, \\ Portland, Oregon, USA, ${ }^{4}$ Now at National Oceanic and Atmospheric Administration, Silver Spring, MD
}

\begin{abstract}
Recent studies of flood risk at New York Harbor (NYH) have shown disparate results for the 100 year storm tide, providing an uncertain foundation for the flood mitigation response after Hurricane Sandy. Here we present a flood hazard assessment that improves confidence in our understanding of the region's present-day potential for flooding, by separately including the contribution of tropical cyclones (TCs) and extratropical cyclones (ETCs), and validating our modeling study at multiple stages against historical observations. The TC assessment is based on a climatology of 606 synthetic storms developed from a statisticalstochastic model of North Atlantic TCs. The ETC assessment is based on simulations of historical storms with many random tide scenarios. Synthetic TC landfall rates and the final TC and ETC flood exceedance curves are all shown to be consistent with curves computed using historical data, within $95 \%$ confidence ranges. Combining the ETC and TC results together, the 100 year return period storm tide at NYH is $2.70 \mathrm{~m}$ (2.512.92 at $95 \%$ confidence), and Hurricane Sandy's storm tide of 3.38 m was a 260 year (170-420) storm tide. Deeper analyses of historical flood reports from estimated Category-3 hurricanes in 1788 and 1821 lead to new estimates and reduced uncertainties for their floods and show that Sandy's storm tide was the largest at NYH back to at least 1700. The flood exceedance curves for ETCs and TCs have sharply different slopes due to their differing meteorology and frequency, warranting separate treatment in hazard assessments.
\end{abstract}

\section{Introduction}

New York Harbor (NYH) and its connected tidal waterways lie at the apex of the New York Bight and are surrounded by over 21 million people in cities such as New York, Newark, Jersey City, and Hoboken. Hurricane Sandy in $\mathbf{2 0 1 2}$ was a harsh reminder of the area's vulnerability to hurricane storm surges. Much of the land immediately surrounding NYH is filled-in former waterways and marshes, or flat coastal plains. The region was recently ranked second in the United States for present-day monetary risk from storm surge [Botts et al., 2013]. Unfortunately, because the last flood comparable to Sandy occurred during the preinstrumental era, in 1821 (Figure 1) [Brandon et al., 2014; Coch, 1994; Scileppi and Donnelly, 2007; Swiss Re, 2014; Talke et al., 2014], Sandy's flood elevation and area came as a surprise to many. Now scientists, insurance companies, decision makers, and citizens across the region are reassessing their flood risk.

There is strong momentum across the U.S. Northeast toward building flood mitigation projects, which require an understanding of coastal flood hazards for determining the design level of protection. New York City developed a $\$ 20$ billion plan for coastal adaptation under the Special Initiative on Rebuilding and Resilience [City of New York, 2013]. This included hundreds of proposed actions to improve resilience, many of which are currently underway. Over $\$ 1$ billion of funding has gone to city and state governments implement the winning projects of the "Rebuild By Design" competition, organized by the federal Department of Housing and Urban Development [e.g., Orff et al., 2014]. Most recently, the US Army Corps of Engineers laid out a set of potential adaptation strategies in the North Atlantic Coast Comprehensive Study (NACCS) report released in early 2015 [USACE, 2015]. Many of these plans seek to provide protection against a 100 year flood or worse.

Researchers have made major advancements in coastal flood hazard assessment methodologies in recent years. Lin et al. [2012] innovated within this area of hazard science by using a dynamical-statistical approach 


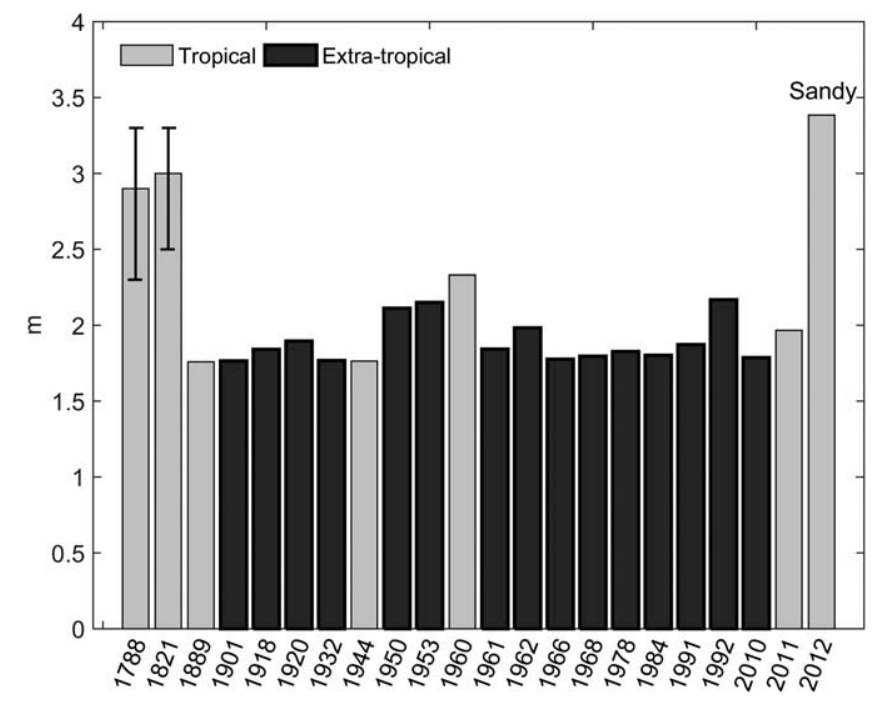

Figure 1. The top 20 gauged historical storm tides from 1844 to 2013 at the Battery (New York Harbor) and the two worst prior events back to 1700 (1788, 1821) were a mixture of extratropical cyclones (ETCS) and tropical cyclones (TCs). Data are water elevation above the year's mean sea level, and 1844-2013 data are based on an updated version of the Talke et al. [2014] data set. Our estimated 1788 and 1821 storm tides have $95 \%$ confidence bars, and are discussed in section 3 . for simulating TCs that can be run with climate model simulations to account for future storm climatology changes. This work showed that future changes to storms could have a similar effect as sea level rise, for worsening flood risk. One of FEMA's [2014b] innovations has been to separately simulate and statistically evaluate TC and ETC flood probabilities in an assessment of total storm tide risk, as the US Mid-Atlantic and New York Bights are known to have severe floods arising from both storm types [Colle et al., 2008, 2010; Dolan and Davis, 1992; Orton et al., 2012]. A subsequent study similarly analyzed flood risk for cold-season and warm-season storms, using data from an innovative Monte Carlo approach to create flood hazard statistics and to demonstrate the substantial seasonal differences in flood risk [Lopeman et al., 2015].

However, the most prominent recent assessments of the present-day flood hazard at New York Harbor (NYH; the Battery tide gauge) disagree in their results, likely in part due to insufficient model validation against observations. Studies that have examined all types of storms have found the 100 year flood to be $2.44 \mathrm{~m}$ (2.19-2.93 $\mathrm{m}$ at 95\% confidence) [Zervas, 2013], and $3.50 \mathrm{~m}$ (with no confidence intervals provided) [FEMA, 2014b]. The Lin et al. [2012] study looked only at TCs and found a present-day 100 year storm tide of $2.03 \mathrm{~m}(1.95-2.11 \mathrm{~m}$ at $90 \%$ confidence), which is substantially different from the same metric in the FEMA study, at $2.75 \mathrm{~m}$. The associated return period estimates for Hurricane Sandy's storm tide range from 100 years [FEMA, 2014b] to $\sim 1500$ years [Zervas, 2013]. These substantial differences in both the TC-only assessments and the complete flood assessments (TC plus ETC) may arise due to insufficient validation of flood modeling for specific historical events—validation of storm tide modeling in the Lin et al. [2012] study was simply referenced to prior studies by other groups [e.g., Colle et al., 2008] and not performed with the specific simplified meteorological modeling methods used in their study. Validation of the FEMA study included evaluations of tides and seven historical storms but did not include the largest storm surge event in the study period of 1938-2009, a 1950 ETC [FEMA, 2014b].

Several challenges complicate any assessment of the storm tide hazard for the region. Compared with the more heavily studied United States Gulf Coast, the larger tides in NYH increase the potential height of storm tides and also increase the magnitude of nonlinear interaction between tides and surge. ETCs are the most common cause of flooding [Colle et al., 2010], a cold-season contribution to flood risk that is often neglected for warmer climates and even for NYH [e.g., Aerts et al., 2014]. TCs produce extremely rare, "Iong-tail" probability distribution events [Lin et al., 2010], that are difficult to predict. The converging New York Bight coastline also adds the potential for amplification of rare events where strong winds blow from the southeast quadrant. However, TC storm tracks typically veer eastward as they approach, so the area has a relative scarcity of historical TC floods upon which to base a hazard assessment. As a result, a hazard assessment method is needed that is not overly reliant on local historical storm tracks, such as is the case with the widely used Joint Probability Method [e.g., Toro et al., 2010].

In this paper, we present a thorough modeling study that quantifies the "present-day" NYH flood hazard. We address the difficulties illuminated above, by separately assessing TCs and ETCs and including detailed validation of modeling and assessment results, ensuring they are consistent with historical observations and assessments, within uncertainty. The present-day storm climatology is based on recent historical ETCs and synthetic TCs. We utilize a new statistical-stochastic TC simulation method that utilizes historical storm 
data from the entire North Atlantic basin (1950-2013) to create a set of synthetic storms that could affect that region. We also use an ETC assessment method where several historical storm events (1950-2009) are simulated with 50 repetitions of random tides, capturing the important contribution of tides to flood levels. Section 2 summarizes methods including storm climatology development, atmosphere and ocean modeling, statistics, and uncertainty quantification. Section 3 is a reassessment of the 1821 hurricane storm tide, as well as a similar but less-studied event in 1788, both useful for model validation and context for Sandy. Section 4 presents study results including validations and exceedance curves (storm tide versus return period), section 5 is a discussion of results that addresses differences between ours and other studies, TC and ETC storm tides, looks at the role of tide-surge interaction, and discusses the implications of the findings regarding the 1788 and 1821 hurricanes, and section 6 lays out the primary conclusions of the study.

\section{Methods}

A detailed operational ocean forecasting system was leveraged to run three-dimensional ocean simulations for a flood hazard assessment that accounts for a full climatology of TCs and ETCs, seasonal cycles of sea level, stratification and air temperature, and a complete range of the region's possible tides. The goal is to accurately estimate storm tides at New York Harbor for return periods from 5 to 10,000 years. Storm tides are defined here as the water elevation above a year's mean sea level. The hazard assessment separately integrates storm tide data over a climatology of TCs and ETCs, then merges the exceedance probabilities to quantify the total flood hazard. This is done because TCs occur less frequently and represent the worst flood events in NYH history, whereas ETCs occur more frequently (many times per year) and represent the more common, less-extreme flood events (Figure 1).

Methods for developing sets of TCs and ETCs representing their present-day storm climatology are described in detail below in sections 2.1 and 2.2, respectively. The historical record may not adequately represent the large TC storm tides, as there have been only a small number of events (Figures 1 and 2a). So we use an ensemble approach where TCs are represented by a large number of synthetic storms created with a statistical model. This model leverages historical TC data from the entire North Atlantic Ocean from 1950 to 2013 to create a 1 million-year (1 My) record of TC activity. A subset of 606 TCs that spans the range of the TC flood hazard was selected from the full storm set, and simple parametric equations are used to represent each TC's wind and pressure forcing for the ocean model. We have no similar synthetic ETC model, but nearly 200 years of historical ETCs have a well-defined range of storm tide with no significant outliers (Figure 1) as long as we consider the powerful hybrid Sandy as part of the TC storm set. This separation enables us to use an existing set of 30 of the worst historical ETC storm surge events from 1950 to 2013 to represent the present-day climatology, as was done by FEMA [2014c]. The worst ETCs are simulated with 50 tide scenarios to capture a near-complete range of possible storm tides for each storm, because of the high importance of tides for ETC flooding in this region (see section 2.4). Meteorological data from atmospheric reanalyses are used for the ETCs as ocean model forcing.

The flood hazard statistics are based on hydrodynamic modeling, described below in section 2.3, instead of historical water levels, for three primary reasons-(1) to merge tides and storm surge dynamically, as described in section 2.4, as well as potentially other factors such as rainfall; (2) to estimate the storm tide over an entire region, not just at tide gauges, thus overcoming a limitation of tide-gauge-based assessments; and (3) to account for realistic storm events and tide/storm combinations that have not occurred in the limited historical record. Synthetic events provide improved estimation of low probability events such as the $1 \%$ annual chance (100 year) storm tide, and even enable estimation of the $0.01 \%$ annual chance $(10,000$ year) storm tide.

A heavy emphasis is placed on model validation using historical events, to leverage historical data and avoid bias. Validation should address the specific coupled ocean-atmosphere simulation methods, as error may exist in the ocean, atmosphere, and their coupling. Rare severe storm tide events are outside the normal range of variability, and thus forecast-oriented ocean models may be tuned toward normal conditions or annually recurring storm conditions. In addition, atmospheric forcing data are typically a strong determinant of storm tide modeling accuracy [e.g., Colle et al., 2015; Orton et al., 2012]. Historical meteorological reanalyses are available for the ETCS [FEMA, 2014a], but simplified wind and pressure fields are used for the TCs, raising the 


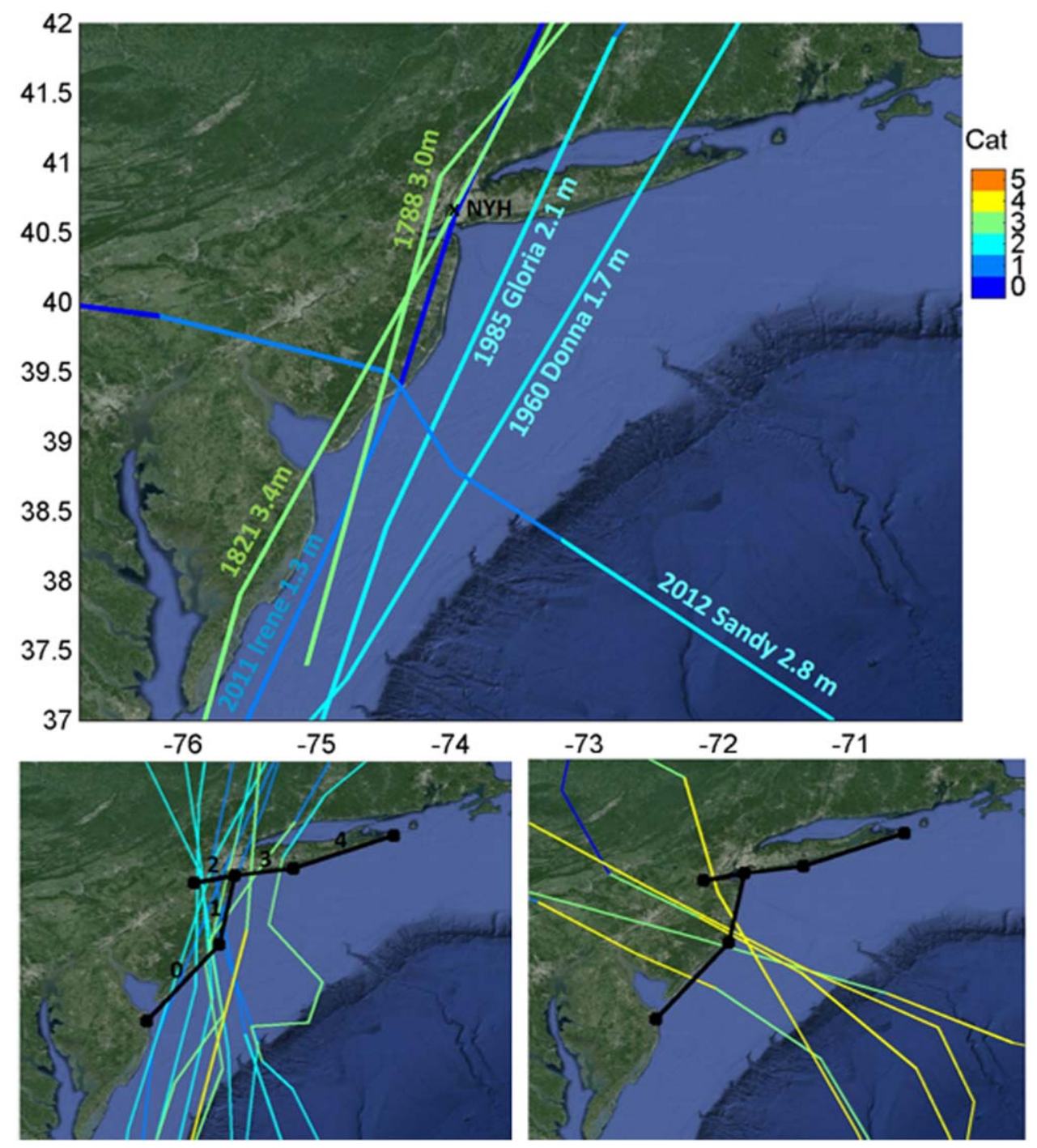

Figure 2. Historical and modeled TC storm tracks affecting New York Harbor (NYH), shaded by Saffir-Simpson category (Cat). (top) Known TC or hybrid TC/ETC 1.25 m or greater surge events at NY Harbor, 1788-2013, with year, name (if any), and observed storm surge. (bottom left) Select modeled TC tracks, on a map that includes the landfall gate numbers. Storms are shown that led to storm tides close to the 100 year event $(2.5-2.9 \mathrm{~m})$ which occur at a rate higher than 0.0001 year $^{-1}$. (bottom right) Storms that led to the largest storm tides in the set, from 5.2 to $5.7 \mathrm{~m}$.

possibility that oversimplification would lead to biases in the storm tide simulations. Historical storm validations for each storm type are given in section 4 , and include 42 historical events. The storm tide error resulting from coupled ocean-atmospheric modeling is then incorporated in uncertainty analyses (section 2.5).

\subsection{TC Modeling and Reduced Storm Set}

TC data are produced using a statistical-stochastic model of the complete life cycle of North Atlantic TCs, initially developed by Hall and Jewson [2007], and extended in Hall and Yonekura [2013]. The model consists of four components: genesis, propagation, and intensity $\left(V_{\max }\right)$ and size $\left(R_{\max }\right)$. Genesis, propagation, and $V_{\max }$ are documented in detail in Hall and Yonekura [2013]. Genesis and propagation are based on optimized local regression of HURDAT data [Landsea et al., 2004] on repeating annual-cycle and interannually varying climate covariates (500 mbar winds, North Atlantic subtropical SST with respect to the global subtropical mean, and ENSO state), while $V_{\max }$ is based on a random sampling scheme with perturbation. A space-date kernel-density PDF modulates the genesis rates to enforce seasonality. $R_{\max }$ is modeled by log regression with $V_{\max }$ and latitude covariates [e.g., Vickery et al., 2000], using extended best-track data, 19982010 [Demuth et al., 2006]. The error term is treated as lag-one autoregression. 
The TC model is developed with historical HURDAT TC data from the entire North Atlantic Ocean from 1950 to 2013 to create a synthetic million-year record of TC activity. The 1950 cutoff represents a compromise between the desire to maximize data quantity and data quality. TC aircraft reconnaissance only began in the late 1940s, and there is evidence for undercounts of nonlandfalling TCs in the earlier part of the HURDAT record [Vecchi and Knutson, 2011]. A cutoff of 1950 should largely avoid these early quality issues.

The probability of a storm's temporal-maximum storm tide $\left(\eta_{\max }\right)$ exceeding a given arbitrary level $(\eta)$ is the multidimensional integral of the hurricane incidence probability times the conditional probability of inundation:

$$
P\left(\eta_{\max }>\eta\right)=\int_{\mathbf{x}} f(\mathbf{x}) P\left(\eta_{\max }(\mathbf{x})>\eta\right) d \mathbf{x}
$$

Here $\mathbf{x}$ is the vector of hurricane hazard variables (e.g., landfall intensity, size, location, bearing, and propagation speed), $f(\mathbf{x})$ is the annual occurrence frequency of hazard $\mathbf{x}$, and $P(\eta(\mathbf{x})>\eta)$ is the conditional probability that a storm of these characteristics will cause a storm tide in excess of an arbitrary value $\eta$. The probability of hurricane event $f$ at $\mathbf{x}$ is determined by the frequency of its set of TC parameters in the large stochastic hurricane set. As it stands, the integral in equation (1) suffers from the "curse of dimensionality." It is too large to solve directly; for example, if $\mathbf{x}$ represents 10 hazard variables, each sampled at 5 values, then there are nearly 10 million $\left(5^{10}\right)$ combinations, or "nodes," at which $P(h \mid \mathbf{x})$ must be evaluated using the hydrodynamic model. As noted in prior studies [e.g., Condon and Sheng, 2012; Toro et al., 2010], approximation methods must be utilized.

Our approach is to limit the number of hazard variables to five, with each coarsely sampled: five landfall gates (Figure 2b), three landfall angles, six categories of intensity (wind speed), three storm sizes, and three storm translation speeds, the latter three variables evaluated at the last $6 \mathrm{~h}$ time step prior to landfall. The intensity categories are 0 for tropical depressions and tropical storms, and 1-5 for the Saffir-Simpson categories. Landfall angles are defined counter-clockwise from gate parallel, and are $0^{\circ}-45^{\circ}, 45^{\circ}-90^{\circ}$, and $90^{\circ}-$ $180^{\circ}$. These are not evenly spaced but have finer divisions for storms heading NW-to- $\mathrm{N}$ across gates 0 and 1 , and NE-to-E across gates 2-4, due to storms having preferred tracks in these directions, versus the larger impact angles. The gates are chosen to capture all possible TC events with surges over $1.25 \mathrm{~m}$ (e.g., Figure $2 \mathrm{a}$ ), capable of causing storm tides exceeding $\sim 2 \mathrm{~m}$. The potential for low bias in our flood assessment, due to missing storms outside these gates, is evaluated at the start of section 5.2. This method is different from studies that use optimal sampling [e.g., Toro et al., 2010], as the storm set is not optimized and leaves us with some storms with very low annual rates. However, our hydrodynamic/wave model is relatively fast compared with the models and resolutions used in that study, and we did not see a need for optimization to reduce the number of storms. Other studies use runs for all storms over a predefined period with a coarse, fast model (SLOSH), then run the most important (e.g., largest) ones using a detailed model [Lin et al., 2010, 2012].

We refer to the specific combination $\mathbf{x}$ of hazard variables as the TC "flavor", and the permutations of the five parameters give a total set of 810 TC flavors. The number of landfalls in each flavor in the million-year data set defines the annual landfall rate simply as the number of events divided by 1,000,000 years. There are 204 storm flavors that are not observed to occur in the data set, so the total storm set of probable storms comprises only 606 storm flavors. For each storm flavor, one storm is randomly selected as a representative event, and several of these tracks are shown in Figure 2. Compared with the total number of storms crossing the five gates in the million-year period, 290,182 TCs, this set of 606 is much more tractable for numerical simulation. To quantify the typical variability of storm tides within a flavor, we separately simulated 50 events for 12 of the TC flavors, discussed below in section 2.5.

Data needed for creating wind, tides, and other forcing data are provided from the Hall TC model, including date and time (for tides and seasonality of temperature and salinity), year (for tides, between 1950 and $2013)$, latitude, longitude, radius of maximum winds $\left(R_{\max }\right)$, and speed of maximum winds $\left(V_{\max }\right)$. Additional parameters needed are the central pressure $\left(P_{\text {central }}\right)$, pressure drop $\Delta P$ (or equivalently, the far-field pressure), and the Holland-B parameter, as described below. The Hall TC data are modeled on the $6 \mathrm{~h}$ time step that is native to HURDAT, so we interpolate the data from $6 \mathrm{~h}$ to $60 \mathrm{~min}$ (SNAP grid; see section 2.3 on ocean model grids) and $15 \mathrm{~min}$ (NYHOPS grid) prior to projection onto the ocean model grids as forcing. The $6 \mathrm{~h}$ 
time step where a TC makes landfall should not be interpolated, as this would lead to a continuous weakening over a $6 \mathrm{~h}$ period, whereas storms weaken more abruptly after making landfall. To avoid interpolation and excessive storm weakening before landfall, wind speeds in the last $6 \mathrm{~h}$ time step before landfall are projected forward without change up to the first $6 \mathrm{~h}$ time step after landfall.

2.1.1. Synthetic TC Pressure Forcing

The Hall TC model has not included central pressure $\left(P_{\text {central }}\right)$ in prior publications, and a model was required here, due to the importance of atmospheric pressure for storm surges. $P_{\text {central }}$ and $V_{\max }$ are tightly, but imperfectly, correlated measures of TC intensity. A variety of regression relationships were tested to relate the central pressure deficit $\left(\Delta P=P_{\text {env }}-P_{\text {central }}\right)$ to $V_{\text {max }}$. A successful candidate was

$$
\Delta P=a_{0}+a_{1} V_{\max }+a_{2} V_{\text {max }}^{2}+a_{3} V_{\text {max }}^{3}+a_{4} \sin (\text { lat })+a_{5} V_{\max } \sin (\text { lat })+\varepsilon
$$

The fitting was performed using HURDAT data from 1900 to 2007 for TCs, and using climatological pressure for the ambient pressure, $P_{\text {env }}$. However, data prior to the 1970 s plays almost no role, as there are few $P_{\text {central }}$ data. To test whether the resulting regression coefficients are significantly different from zero, a generalized jackknife test was employed, in which the model is refit multiple times with random $80 \%$ subsets of the data. We found that the linear term $\left(a_{1}\right)$ is not significantly different than zero, but the remaining terms are. Thus, the model we use is

$$
\Delta P=a_{0}+a_{2} V_{\max }^{2}+a_{3} V_{\max }^{3}+a_{4} \sin (\text { lat })+a_{5} V_{\max } \sin (\text { lat })+\varepsilon
$$

Here $a_{0}=-1.627, a_{2}=0.0197, a_{3}=-7.448 \mathrm{E}-5, a_{4}=6.587$, and $a_{5}=0.542$ for units $V_{\max } \mathrm{m} \mathrm{s}^{-1}$ and $P_{\text {central }}$ in $\mathrm{hPa}$. The error $(\varepsilon)$ term constitutes the stochastic component of the model. It is $\varepsilon=\sigma x(t)$, where $\sigma$ is the RMS variance of the residuals, the anomaly $x(t)$ is lag-one autocorrelation $(A R(1))$ : $x(t)=c^{*} x(t-1)+\operatorname{sqrt}\left(1-c^{2}\right) \varepsilon, c$ is the autocorrelation coefficient (ACC), and $\varepsilon$ the standard normal forcing. We found the best results by making $\sigma$ depend on $V_{\text {max }}: \sigma=b_{0}+b_{1} V_{\text {max }}$. The error-model coefficients are fit by an iterative process to minimize overall model variance from observations, and are $b_{0}=0.944, b_{1}=0.161$, and $\mathrm{ACC}=0.655$.

The model we use for radial profiles of pressure, $P(r)$, is Holland [Holland, 1980].

$$
P(r)=P_{\text {central }}+\Delta P \exp \left\lceil-\left(\frac{R_{\max }}{r}\right)^{B}\right\rceil
$$

Here it is assumed that the exponential pressure profile radius is equal to the radius of maximum winds $\left(R_{\max }\right)$, though for moderate-sized and large-sized storms, the pressure radius becomes larger. The differences are small relative to the natural scatter in both variables [FEMA, 2014c]. Parameter B controls the profile shape, and is related to the maximum wind speed and pressure deficit [Holland, 1980]:

$$
\mathrm{B}=V_{\max }^{2} \rho \exp (1) / \Delta P
$$

Here $\rho$ is air density, computed from seasonally varying air temperature.

\subsubsection{Synthetic TC Wind Forcing}

The Sea, Lake, and Overland Surges from Hurricanes (SLOSH) wind profile model [Jelesnianski et al., 1992] can be expressed as

$$
V_{\text {vortex }}(r)=V_{\max , \text { sym }} \frac{2 R_{\max } r}{R_{\max }^{2}+r^{2}}
$$

Here $V_{\text {vortex }}$ is the vortex wind speed, $r$ is the radial location, $V_{\text {max,sym }}$ is the symmetrical maximum wind speed, and $R_{\max }$ is the radius of maximum wind. The relationship between the symmetrical maximum wind speed and the maximum wind speed is

$$
V_{\max , \text { sym }}=V_{\max }-\alpha V_{\text {storm }}
$$

Here $\alpha$ is the background wind modification factor, and $V_{\text {storm }}$ is the storm translation speed. Departing from normal NWS SLOSH wind modeling, for the contribution of the background winds, we add the background wind velocity to the vortex wind velocity after using an empirical estimate of inflow angle of $20^{\circ}$, and a modification factor $\alpha$ of 0.55 , shown to be more accurate representations of modeled wind and storm surge [Lin and Chavas, 2012]. 

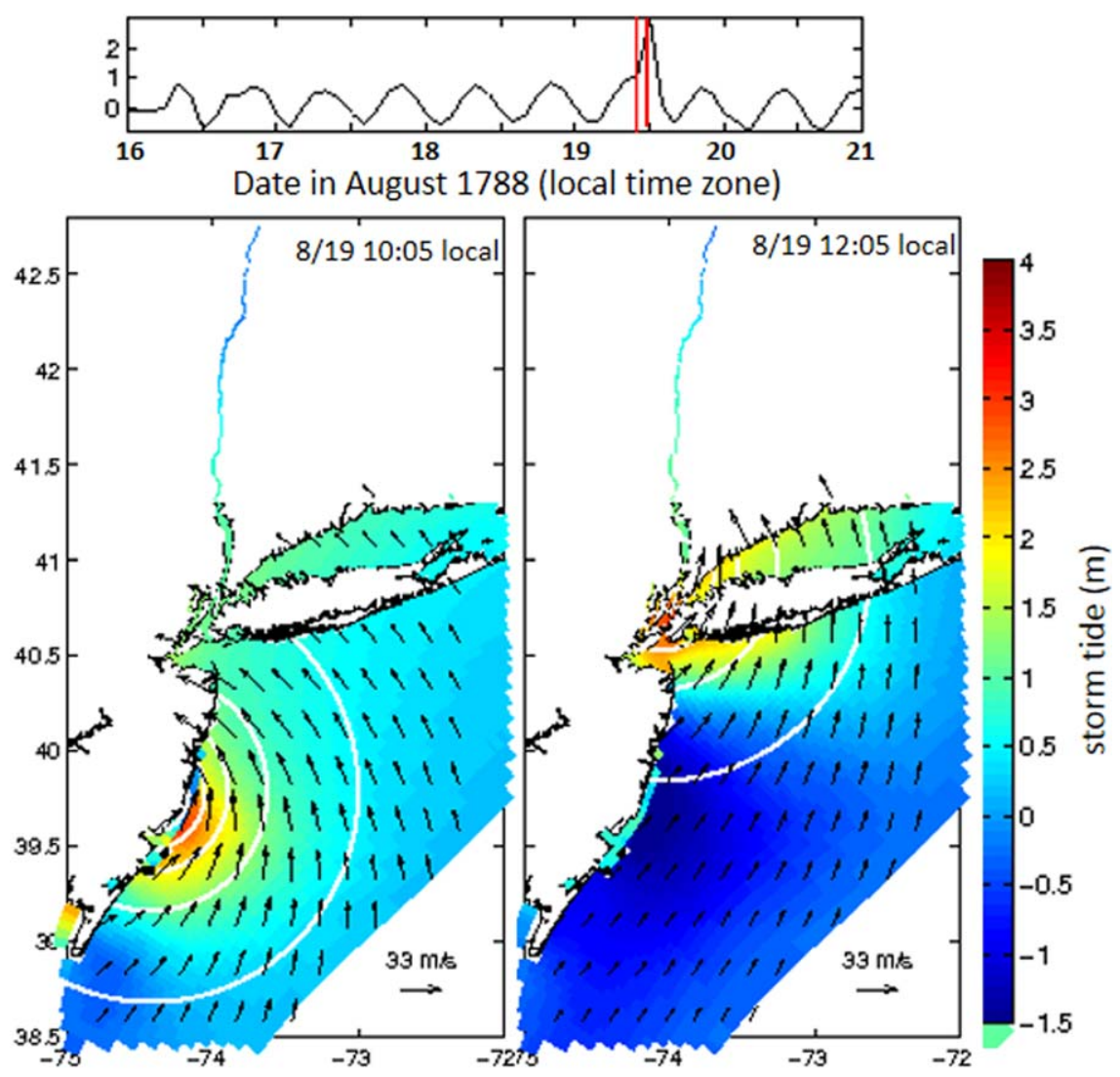

Figure 3. Estimated 1788 hurricane meteorology and modeled storm tide (elevation) shading and time series at NYH (NYHOPS model domain), for two snapshots in time. Wind velocity is shown as vectors (see $33 \mathrm{~m} / \mathrm{s}$ key at bottom right) and pressure isobars are shown as white lines. The red vertical lines in the time series show the times represented in the maps. See section 3.2 for a summary of the storm's history and data sources.

An empirical model of wind inflow angle is applied to the TC vortex winds [Bretschneider, 1972; Phadke et al., 2003]. Lastly, the TC vector wind velocity is the vector sum of the vortex wind velocity $\left(\boldsymbol{V}_{\text {vortex }}\right)$ and background wind velocity $\left(\boldsymbol{V}_{\text {storm }}\right)$ [Lin and Chavas, 2012]:

$$
\boldsymbol{V}_{\boldsymbol{T C}}=\boldsymbol{V}_{\text {vortex }}+\alpha \boldsymbol{V}_{\text {storm }}
$$

TC maximum wind speed in the HURDAT database and from the Hall model is the 1 min maximum sustained wind, yet the ocean model requires $10 \mathrm{~min}$ averages, so winds were reduced by a 0.93 factor to account for gustiness [Harper et al., 2010]. This is done because the 1 min maximum sustained wind is actually a gust, and because the model's wind stress is computed using a drag law that was developed using 10 min average winds. An example of synthetic TC wind forcing applied to a historic storm, the 1788 hurricane, is shown in Figure 3, and validation of historical TCs with these methods is covered in section 4.

\subsection{ETC Modeling and Storm Set}

A set of 30 regionally severe ETC storm surge events from 1950 to 2009 was recently created for the FEMA [2014b] study, with reanalyses of wind and surface pressure created by Oceanweather, Inc. The reanalyses were constructed using the Interactive Objective Kinematic Analysis system and a wide variety of data (e.g., buoy, satellite), as described in Cox et al. [1995], and summarized in the recent FEMA [2014a] report. These 30 ETCs were selected from a 60 year period (1950-2009), so each storm is given an annual rate of $1 / 60$ year $^{-1}$ in the assessment, following a peaks-over-threshold type assessment approach [Pickands, 1975]. We use hindcasts with historical tides for validation, but for the hazard assessment we simulate each storm with random tides and the 19 largest ETC surge events are simulated 50 times with different random tides, as explained in section 2.4.

The FEMA ETC storm set we use here includes 8 of the top 10, and 19 of the top 30 ETC surge events at the NYH Battery tide gauge in the period 1950-2009 (Table 1). Some events are missing due to unavailability of 
Table 1. ETC Storm Set, Including the Number of Tide Repetitions (Section 2.4), and in Cases Where a Storm's Annual Rate Was Doubled, the Missing Storm That is Accounted for (Doubling Storm)

\begin{tabular}{|c|c|c|c|c|c|c|c|c|}
\hline \# & $\begin{array}{c}\text { Code } \\
\text { yyyymmdd }\end{array}$ & Year & Month & $\begin{array}{l}\text { Day of } \\
\text { Peak }\end{array}$ & $\begin{array}{c}\text { Battery } \\
\text { Surge }^{a}(m)\end{array}$ & $\begin{array}{l}\text { Surge } \\
\text { Rank }^{\text {b }}\end{array}$ & $\begin{array}{l}\text { Tide } \\
\text { Reps }\end{array}$ & $\begin{array}{l}\text { Doubling } \\
\text { Storm }\end{array}$ \\
\hline 1 & 19501125 & 1950 & 11 & 25 & 2.41 & 1 & 50 & \\
\hline 2 & 19610413 & 1961 & 4 & 13 & 1.15 & 18 & 50 & 19551014 \\
\hline 3 & 19620306 & 1962 & 3 & 6 & 1.26 & 13 & 50 & 19610204 \\
\hline 4 & 19640112 & 1964 & 1 & 12 & 0.99 & 40 & 1 & \\
\hline 5 & 19660123 & 1966 & 1 & 23 & 1.07 & 27 & 50 & 19660130 \\
\hline 6 & 19681112 & 1968 & 11 & 12 & 1.49 & 6 & 50 & 19801025 \\
\hline 7 & 19701217 & 1970 & 12 & 17 & 0.96 & 41 & 1 & \\
\hline 8 & 19710208 & 1971 & 2 & 8 & 1.17 & 17 & 50 & 19851105 \\
\hline 9 & 19711125 & 1971 & 11 & 25 & 1.13 & 21 & 50 & 19780120 \\
\hline 10 & 19720219 & 1972 & 2 & 19 & 1.06 & 30 & 50 & 19721108 \\
\hline 11 & 19741202 & 1974 & 12 & 2 & 1.7 & 3 & 50 & \\
\hline 12 & 19790125 & 1979 & 1 & 25 & 1.3 & 12 & 50 & \\
\hline 13 & 19840329 & 1984 & 3 & 29 & 1.57 & 4 & 50 & 19531107 \\
\hline 14 & 19870123 & 1987 & 1 & 23 & 1.07 & 29 & 50 & 19940104 \\
\hline 15 & 19911031 & 1991 & 10 & 31 & 1.41 & 8 & 50 & \\
\hline 16 & 19921211 & 1992 & 12 & 11 & 1.83 & 2 & 50 & \\
\hline 17 & 19930314 & 1993 & 3 & 14 & 1.39 & 9 & 50 & \\
\hline 18 & 19940303 & 1994 & 3 & 3 & 1.15 & 19 & 50 & 19960320 \\
\hline 19 & 19941224 & 1994 & 12 & 24 & 0.93 & 50 & 1 & \\
\hline 20 & 19950204 & 1995 & 2 & 4 & 0.8 & 103 & 1 & \\
\hline 21 & 19951115 & 1995 & 11 & 15 & 1.32 & 10 & 50 & \\
\hline 22 & 19960108 & 1996 & 1 & 8 & 1.31 & 11 & 50 & \\
\hline 23 & 19961020 & 1996 & 10 & 20 & 1 & 39 & 1 & \\
\hline 24 & 19961206 & 1996 & 12 & 6 & 1.04 & 32 & 1 & \\
\hline 25 & 19980128 & 1998 & 1 & 28 & 0.76 & 123 & 1 & \\
\hline 26 & 19980205 & 1998 & 2 & 5 & 1.03 & 34 & 1 & \\
\hline 27 & 20051025 & 2005 & 10 & 25 & 1.1 & 25 & 50 & 19600219 \\
\hline 28 & 20070416 & 2007 & 4 & 16 & 0.98 & 42 & 1 & \\
\hline 29 & 20080512 & 2008 & 5 & 12 & 0.84 & 80 & 1 & \\
\hline 30 & 20091113 & 2009 & 11 & 13 & 0.9 & 66 & 1 & \\
\hline
\end{tabular}

${ }^{\text {a }}$ Surge is the peak water elevation minus tide, minus annual mean sea level.

${ }^{b}$ ETC surge rankings are for the period 1950-2013, the period of the reanalysis data sets.

good marine meteorological data for the earlier periods (1950s and 1960s), and some are missing because the FEMA study was a regional study with the goal of creating a storm set for the entire study area of New Jersey and the New York City region including western Long Island Sound, not only for NYH. To account for the two missing storms in the top 10, the annual occurrence rates of two storms with similar surges were simply doubled in the statistical analysis. The surge ranked \#5 for 1950-2009 was missing (19531107; $1.53 \mathrm{~m}$ surge) and was replaced by doubling the rate of \#4 (19840329; $1.57 \mathrm{~m})$; \#7 was missing $(19801025 ; 1.47 \mathrm{~m})$ and replaced by doubling the rate of \#6 (19681112; $1.49 \mathrm{~m})$. Similarly, nine storms ranked in the \#11-30 range were missing, so nine storms' rates were doubled for the statistical analysis (see Table 1). Lower surge events (below the top 30 in the 60 year period) are not fully represented in the statistical analysis, but appear to have little effect on the tail of the distribution which is of interest for 5 year and longer return periods.

Hybrid TC/ETC storms are classified differently in our study depending on how they are represented in the HURDAT database. While Sandy officially became an ETC just prior to landfall [Blake et al., 2013], we include Sandy in the assessment as a TC because Sandy is in the HURDAT database and its entire life cycle until landfall is part of the data that informs our statistical TC model. On the other hand, the 19911031 ("The Perfect Storm") is in the ETC set, though it was associated with a hurricane. According to HURDAT, the storm was purely an ETC up to the time of the peak storm surge at NYH, and only later did it transition to a hybrid storm. This storm had only a moderate surge at NYH of $1.41 \mathrm{~m}$ (ETC rank: \#8; Table 1). Its data do not inform the statistical TC model because by the HURDAT database it began as an ETC and later became a TC. The impact of this separation is addressed in section 5.3.

\subsection{Detailed Ocean Modeling Using the NYHOPS System}

The Stevens ECOM (sECOM) three-dimensional hydrodynamic model [Blumberg et al., 1999; Georgas and Blumberg, 2009; Georgas et al., 2014; Orton et al., 2012] has been providing highly accurate storm surge 


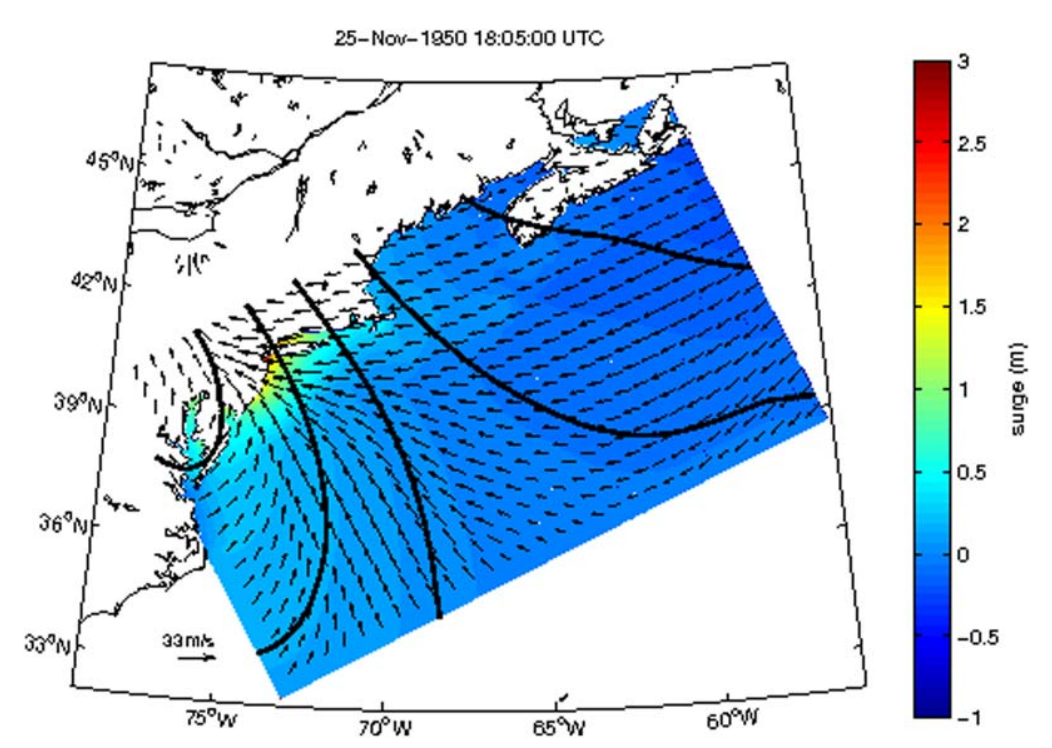

Figure 4. The 1950 ETC meteorological reanalysis and modeled storm surge on the SNAP grid, near the time of peak surge. Wind velocity is shown as vectors, and pressure isobars as black lines. All storms in the study were simulated with only storm surge on the SNAP grid and then on the nested NYHOPS grid with tides.

forecasts on its NYHOPS grid/domain (http://stevens.edu/NYHOPS) for over a decade with typical water level errors of $0.10 \mathrm{~m}$ [Georgas and Blumberg, 2009]. The NYHOPS domain includes the Mid-Atlantic and Northeastern U.S. coastline from Maryland to Rhode Island (e.g., Figure 3). The NYHOPS sECOM domain includes measured or modeled freshwater and heat inputs from 544 sources including tributaries, power plants, wastewater treatment plants, and sewer inputs [Georgas and Blumberg, 2009; Georgas, 2010].

A major uncertainty in storm surge modeling is the sea surface drag coefficient parameterization [Cardone and Cox, 2009; Lin and Chavas, 2012; Resio and Westerink, 2008]. Hindcast studies of two recent TCs with sECOM on the NYHOPS grid have found that replacing the wind drag parameterization used by the operational system [Large and Pond, 1981] with a wave-slope sensitive parameterization [Taylor and Yelland, 2001] gives improved results and RMS errors of $0.15 \mathrm{~m}$ for Tropical Storm Irene [Orton et al., 2012], and $0.17 \mathrm{~m}$ for Hurricane Sandy [Georgas et al., 2014], and the latter is used here. Recent studies have presented evidence that the drag coefficient hits a ceiling at high wind speeds [e.g., Powell et al., 2003], but this saturation has not been demonstrated for the shallow coastal ocean. Cardone and Cox [2009] point out that, due to uncertainties in wind and air-sea interaction physics, it is common to tune the drag coefficient ceiling based on model validations. Here we find that the best fit for historical TCs (measured with RMS error) is attained with a drag coefficient ceiling of 0.0035 . We use the same ceiling value for ETCs in this study, although the choice of ceiling value has a much smaller effect on ETC storm tides because the ETC wind drag here almost never exceeds 0.0025 .

Modeling of each storm with SECOM is first performed on the Stevens Northwest Atlantic Predictions (SNAP) grid that extends to the Gulf of St. Lawrence and Cape Hatteras and $\sim 2000 \mathrm{~km}$ offshore. Having a domain of this large extent can be crucial for remote sea level forcing for large TCs and for all ETCs (Figure 4). For the SNAP grid, sECOM is run with wind and pressure forcing (no tides or streamflows), with constant ocean temperature and salinity. Water elevation boundary conditions are based on a local inverse barometer calculation using atmospheric pressure.

The modeling on the nested NYHOPS grid is set up with clamped offshore water elevation boundary conditions that are a sum of time series of tides, surge from the SNAP domain, and mean observed seasonal variations in mean sea level, which vary from $-10 \mathrm{~cm}$ (January) to $+7 \mathrm{~cm}$ (September). All model runs for TCs are 6 days, allowing for 3.5 days spin-up time prior to storm landfall. Model runs for ETCs are 10 days, allowing for similar spin-up time but longer storm durations. Vertically and spatially varying ocean initial conditions (salinity and temperature) and a spatially constant air temperature (important to wind stress) are set as seasonally varying climatological values. Freshwater inputs have only a very small effect on temporal- 
maximum NYH storm tides, on the order of a few centimeters [Orton et al., 2012], but modeled (TCs) and historical values (ETCS) were utilized to avoid any bias. SECOM is coupled with a modified form of the DoneIan [1977] wave model [Georgas et al., 2007; Georgas and Blumberg, 2009; Orton et al., 2012], including wave-slope sensitive wind stress as mentioned above [Taylor and Yelland, 2001] and wave-current bed stress. Bed stress is adjusted due to wave-current interaction based on the theory of Grant and Madsen [Grant and Madsen, 1979], simplified by assuming colinear waves and currents [Signell et al., 1990]. However, wave setup of sea level due to breaking waves is not included. Inside a harbor like NYH with a wide deep entrance, wave setup is not expected to be large and one prior published study found a contribution to storm tide that averaged below 1.5\% [Lin et al., 2012]. Nevertheless, this constitutes a low bias, and its elimination is discussed in section 5 .

\subsection{Tide Forcing}

Tides were included in hydrodynamic simulations for each storm, to fully account for their well-known nonlinear interaction with storm surge [e.g., Horsburgh and Wilson, 2007; Pugh, 1987; Tang et al., 1996]. The tides are modeled as normally is the case with the NYHOPS forecasting system, using nine constituents, equilibrium arguments and nodal factors to accurately cover semidiurnal, diurnal, spring-neap, monthly, and interannual variations [Georgas and Blumberg, 2009]. Tide time series are imposed at the NYHOPS grid's offshore boundary and based on the EC2001 tide database [Mukai et al., 2002].

For ETCs, to include a wide variety of random tide-surge phasing and build a smoother rate distribution for the statistical analysis, the 19 most intense storms (largest historical surge) were each simulated 50 times with different random tides from any date in this same year range (Table 1). Each of these storms' annual rates was correspondingly divided by 50 in the statistical analysis. The remaining 12 storms are simulated only once and kept in the storm set for validation and for future studies of broader regional interest (e.g., the New Jersey coast), but have only a small influence on the area of the storm tide distribution that is relevant for 5 year and longer return period events.

With TCs, where we have a much larger storm set (606 storms), we use a computationally inexpensive approach of simulating only one random tide, but smoothing the probability distribution to account for tide variability. We randomly select a tide time series within hurricane season from 1950 to 2013 . The distribution smoothing is done within the same framework as used for random storm selection (section 2.1), by including random tides in the simulations of the 50 events for 5 of the TC flavors, discussed further in section 2.5. This simplified smoothing approach for tides may lead to greater uncertainty, but on average the tides account for $36 \%$ of the peak ETC water levels in Figure 1, relative to only $10 \%$ for the TCs, and a prior study has noted a decreasing importance of tides for increasingly large TC storm tide events [Lin et al., 2012].

\subsection{Statistical Analysis and Assessment Uncertainty}

Temporal-maximum storm tides $\left(\eta_{\text {max }}\right.$ ) were compiled for each model run's 10 min outputs data sets for analysis using exceedance statistics. Rate distributions (similar to probability distributions) were formed from these data and each storm's annual rate. Similar to Niedoroda et al. [2010], we do not use fitted distribution types in place of the resulting empirical rate distributions of storm tides, because we do not want to enforce a theoretical shape on the distribution when the results of the physical models can define it instead. Moreover, we are representing the tails smoothly, in the case of ETCs by using a large number of random tide simulations, and in the case of TCs with a large number of storm flavors, and smoothing, described below. The inverse cumulative rate distribution is equivalent to the exceedance probability curve, and these are presented in section 4.3 with return periods (inverse probabilities), as flood exceedance curves.

Each of the 606 TC flavors was represented using only one TC and one random tide event, as explained above. Each modeled storm tide result represents $\eta_{\max }(\mathbf{x})$ in equation (1) as a single value, yet one should ideally represent all the possible tides and TCs that occur within a flavor, and represent $\eta_{\max }(\mathbf{x})$ as a distribution of values instead. To study the distributions for a range of TC storm tides, we separately simulated 50 events for 12 of the TC flavors, with four $\sim 1.5 \mathrm{~m}$, four $\sim 2.1 \mathrm{~m}$, and four $\sim 2.7 \mathrm{~m}$ TC flavors (average storm tide within the flavor). The chosen flavors were chosen to span both the New Jersey and Long Island coasts and have relatively high rates of occurrence (above 0.0001 year $^{-1}$ ). The storm flavors were segregated into these three categories, and data for each flavor were differenced with their mean and merged to view the 


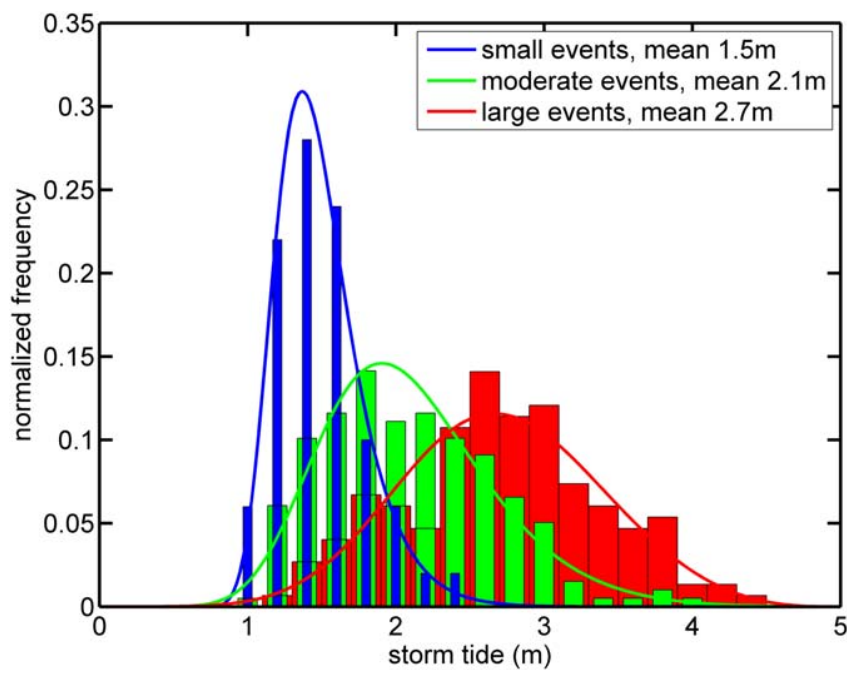

Figure 5. Characterization of spread in modeled TC storm tides within a storm flavor. Three GEV-fitted distributions are shown that cover a range of storm intensities, each including 200 cases of randomly chosen storms and tides. These curves are later used for TC rate-distribution smoothing. aggregate distribution of TC storm tides for each of the three categories. These aggregated distributions were fit with Generalized Extreme Value (GEV) distributions, shown in Figure 5, and show that the larger events were approximately Gaussian, the smaller events exhibited a positive skew, and the moderate events had a positive skew with a long tail. The standard deviations of the small, moderate, and large events were $0.29,0.58$ and $0.67 \mathrm{~m}$, respectively. These results show a clear "floor" on storm tides at about $1.0 \mathrm{~m}$, which is due to tidal variations; high tide is typically $0.5-1.0 \mathrm{~m}$ above mean sea level, and a surge event leads to higher values. The raw TC rate distribution is smoothed using these three GEV distributions, interpolated to cover the entire range of storm tide-GEV distribution parameters for the $1.5 \mathrm{~m}$ case were used for smoothing the TC storm tide distribution from 0 to $1.5 \mathrm{~m}$, interpolated between 1.5 and $2.7 \mathrm{~m}$, and parameters for the $2.7 \mathrm{~m}$ case were used for smoothing the distribution at $2.7 \mathrm{~m}$ and above.

Uncertainty in the final TC flood exceedance curve was quantified as the spread above and below the median using 1000 Monte Carlo simulations, where in each case random Gaussian noise with a standard error equal to the total uncertainty was added. This uncertainty is the combination of RMS error in the validation, in the annual rates of each TC flavor, and in the use of using a single random tide and single storm per TC flavor. Regarding the annual TC rates, based on the TC model jackknife uncertainty analysis in Hall and Sobel [2013] we use a $\pm 20 \%$ ( \pm 2 sigma) uncertainty at the 0.01 year $^{-1}$ rate, linearly increasing to $\pm 80 \%$ at 0.00001 year $^{-1}$. Regarding the use of a single tide and storm per TC flavor, we use standard deviations described above and illustrated in Figure 5.

Uncertainty in the final ETC flood exceedance curves was also quantified using 1000 Monte Carlo simulations, including a bootstrap resampling of historical events, of which there were effectively 41 after the doubling of rates for 11 storms. Random Gaussian noise was first added to results of each of the simulated storms, with a standard deviation equal to the RMS error in the validation $(0.19 \mathrm{~m})$. By running 50 iterations with random tides for all the important ETCs, it is assumed that uncertainty due to the contribution of random tide assignment is negligible.

\section{Reassessment of Extreme NYH Storm Tides Back to 1700}

Multiple hurricanes flood events in the 18th and 19th centuries [Brandon et al., 2014; Scileppi and Donnelly, 2007] suggest that large, possibly Hurricane Sandy magnitude events may occur once every order-of-100 years, so a better understanding of these rare extreme events is needed to understand flood risk in $\mathrm{NYH}$. Qualitative historical storm and flood reports for NYH are available from newspapers and historical archives, and have been extensively reviewed [Boose et al., 2001; Kussman, 1957; Ludlum, 1963]. Estimates of wind velocity are also available for all events affecting the New England and NYC area back to the 1600s [Boose et al., 2001; Boose et al., 2003]. These data suggest that the estimated Category-3 hurricanes of 1788 and 1821 exceeded $2.5 \mathrm{~m}$ and possibly even $3.0 \mathrm{~m}$ storm tides [Kussman, 1957; Ludlum, 1963; Scileppi and Donnelly, 2007].

To better understand and constrain the contribution of the 1788 and 1821 events to flood hazard, we reassess available archival data below (sections 3.1-3.2) and then simulate these events using best available data to check archival estimates (section 4.2). To ensure against model bias, we apply the same modeling 
approach to reassess an August 1893 Category-1 hurricane whose storm track passed directly over NYH, as well as several other TC events. Such validation is necessary because archival estimates based on contemporary accounts can be mistaken; for example, the 1893 event was long thought to have caused a storm tide of $3.0 \pm 0.5 \mathrm{~m}$ at NYH [Scileppi and Donnelly, 2007] but was recently shown to have registered a peak storm tide of only $1.6 \mathrm{~m}$ at NYH [Talke et al., 2014].

\subsection{The 1821 Norfolk and Long Island Hurricane}

Records suggest that the 1821 hurricane struck NYH at low water, with peak winds occurring between 6 and 7:30 P.M. [Espy, 1839; Redfield, 1831]. Data for the storm such as wind magnitude, direction, and track were also compiled by Redfield [1831], Espy [1839], and modern sources [Boose et al., 2001, 2003; Kussman, 1957; Ludlum, 1963; Swiss Re, 2014], and suggest a fast moving storm eye ( $\left.\sim 50 \mathrm{~km} \mathrm{~h}^{-1}\right)$ with a large storm surge or storm tide from Norfolk $(3 \mathrm{~m})$ to New York. Using 19th century hourly tide data from Governors Island (NYH) to compute the tidal constituents [see Talke et al., 2014], we hindcast that a low tide of approximately $-0.4 \mathrm{~m}$ below sea level would have occurred at approximately 18:45 local time (EST) on 3 September 1821.

Wind speed measurements were not available during the 1821 storm, but dozens of observers along the U.S. East Coast made detailed observations of wind direction (eight points of the compass), qualitative reports of speeds, and detailed reports of damages [Ludlum, 1963]. These have recently been summarized [Boose et al., 2001; Elsner, 2006], and two estimated time series of storm location, maximum wind speed, and radius-to-maximum-wind have been derived based on this information [Boose et al., 2003]. Upon arrival at NYC, Boose et al. [2003] estimate a $R_{\max }$ of $50 \mathrm{~km}$, a $V_{\max }$ of $51.4 \mathrm{~m} \mathrm{~s}^{-1}$ (a weak Category-3 hurricane), and a storm translation speed of $12 \mathrm{~m} \mathrm{~s}^{-1}$. Separately, central pressure, $R_{\max }$ and translation speed near landfall have been estimated to be $965 \mathrm{mbar}, 56 \mathrm{~km}$, and $15 \mathrm{~m} \mathrm{~s}^{-1}$, respectively [Elsner, 2006].

A recurrent misunderstanding about the extreme water levels at NYH produced by the 1821 event stems from Redfield [1831], who states that "a 13 foot storm tide occurred from low water." Subsequent investigations have interpreted low water as the predicted low tide of $-0.4 \mathrm{~m}$ on 3 September, which implies that a storm tide of $13 \mathrm{ft}(3.96 \mathrm{~m})$ reached a height of approximately $3.2 \mathrm{~m}$ above MSL 1821 [Ludlum, 1963; Scileppi and Donnelly, 2007]. However, contemporary newspapers upon which Redfield [1831] is based reported an exact surge of $13 \mathrm{ft}, 4 \mathrm{in}$. $(4.0 \mathrm{~m}$ ) in the East River relative to low water mark (The Gazette and General Advertiser, 7 September 1821) [see Boose et al., 2003; Kussman, 1957]. Here as suggested also in Kussman [1957], we assert that the low water mark (LWM) was most likely an extreme low water datum, rather than the predicted low water for the evening of 3 September 1821.

The inference of an LWM datum is supported by nautical maps such as Blunt's American Coast Pilot of 1827 , or the US Coastal Survey map of 1844 . These early maps, which referenced their depths to tidal datums using tide measurements, base their topography on an extreme low water datum called "low water." The 1844 Hassler map datum explicitly uses the measured spring low water on 23 and 24 October 1835 , which harmonic analysis suggests was approximately $-1.0 \mathrm{~m}$ below MSL 1835 . Considering typical variation between measured and predicted tides, we suggest that the $L W M$ datum used pre-1850 was approximately $-1.0 \pm 0.2 \mathrm{~m}$ below MSL 1821 . We further assume that the 1821 measurement of $4.0 \mathrm{~m}$ carries a precision of $\pm 0.2 \mathrm{~m}$ (we consider it probable that the storm tide estimate was made after the fact based on water-line or debris-line measurements, rather than direct observation, given the severity of the event and the 4 day time lag before the number was published).

Considering these factors, we estimate that the storm tide of 3 September 1821 was approximately $3.0 \mathrm{~m}$ (2.5-3.3 $\mathrm{m}$ at $95 \%$ confidence) (Table 2 ) and represents a storm surge of 3.4, or $0.6 \mathrm{~m}$ larger than the hurricane Sandy storm surge. Our storm tide estimate approximately agrees with the Kussman [1957] storm tide estimate of 2.7-3.0 m relative to MSL 1821, based on contemporary flooding accounts of structures, and is within the error bounds of the $3.2 \pm 0.5 \mathrm{~m}$ estimate of Scileppi and Donnelly [2007]. Because mean sea level at the Battery was $0.50 \mathrm{~m}$ lower in 1821 than 2012 [Kemp and Horton, 2013], and the storm tide was $0.4 \mathrm{~m}$ smaller (Table 2), the 1821 peak water elevation was $0.9 \mathrm{~m}$ lower than Sandy in absolute terms.

\subsection{The 1788 Hurricane}

News accounts and data compiled by Boose et al. [2001] and Ludlum [1963] describe a small and fast hurricane that made landfall in Delaware Bay and traveled overland to NYH, parallel to the coast. "The storm that 


\section{QAGU Journal of Geophysical Research: Oceans}

\begin{tabular}{|c|c|c|c|c|c|c|c|c|c|c|c|}
\hline$\#$ & Year & Name & Month & Day & $\begin{array}{c}R_{\max }{ }^{\mathrm{a}, \mathrm{f}} \\
(\mathrm{km})\end{array}$ & $\begin{array}{c}V_{\max }^{a, b, g} \\
(m / s)\end{array}$ & $\begin{array}{c}P_{\text {central }}{ }^{\mathrm{a}, \mathrm{g}} \\
\text { (mbar) }\end{array}$ & $\begin{array}{c}V_{\text {storm }}{ }^{a, g} \\
(\mathrm{~m} / \mathrm{s})\end{array}$ & $\begin{array}{c}\text { Bearing }^{\mathrm{g}} \\
\left({ }^{\circ}\right)\end{array}$ & $\begin{array}{c}\text { Max } \\
\operatorname{Surge}^{c}(m)\end{array}$ & $\begin{array}{c}\text { Max Storm } \\
\operatorname{Tide}^{c}(\mathrm{~m})\end{array}$ \\
\hline 1 & 1788 & Unnamed & 8 & 19 & 29 & $51.4^{e}$ & $952^{d}$ & $17.6^{\mathrm{e}}$ & $16^{\mathrm{e}}$ & 3.0 & 2.9 \\
\hline 2 & 1821 & Unnamed & 9 & 3 & $50^{e}$ & $51.4^{\mathrm{e}}$ & $952^{d}$ & $11.1^{\mathrm{e}}$ & $23^{e}$ & 3.4 & 3.0 \\
\hline 3 & 1893 & Unnamed & 8 & 24 & $50^{e}$ & 41.2 & 978 & 10.4 & 9 & 1.2 & 1.6 \\
\hline 4 & 1938 & Unnamed & 9 & 21 & 55 & 45.3 & 940 & 22.6 & 359 & 1.22 & 1.68 \\
\hline 5 & 1944 & Unnamed & 9 & 15 & 51 & 46.3 & 955 & 13.1 & 30 & 1.18 & 1.76 \\
\hline 6 & 1954 & Carol & 8 & 31 & 48 & 43.4 & 963 & 15.6 & 18 & 0.89 & 1.29 \\
\hline 7 & 1960 & Donna & 9 & 12 & 101 & 43.5 & 961 & 17.5 & 25 & 1.69 & 2.33 \\
\hline 8 & 1976 & Belle & 8 & 10 & 49 & 42.3 & 975 & 11.6 & 12 & 1.21 & 1.29 \\
\hline 9 & 1985 & Gloria & 9 & 27 & 69 & 44.2 & 950 & 19.2 & 20 & 2.17 & 1.71 \\
\hline 10 & 1999 & Floyd & 9 & 16 & 139 & 30.9 & 974 & 15.2 & 28 & 1.14 & 1.11 \\
\hline 11 & 2011 & Irene & 8 & 28 & $185^{\mathrm{h}}$ & 28.3 & 963 & 12.0 & 19 & 1.26 & 1.97 \\
\hline 12 & 2012 & Sandy & 10 & 29 & $204^{\mathrm{h}}$ & 41.2 & 940 & 8.1 & 320 & 2.76 & 3.38 \\
\hline
\end{tabular}

began on Monday, continued on Tuesday, and augmented to a greater degree of violence, wind at SE and ESE. At half past 11 increased to a perfect gale, which raged near half an hour with irresistible fury. Shipping would have been greatly damaged had not the wind shifted suddenly to E.N. and NW about mid-day" (The Providence Gazette and Country Journal, Tuesday, 30 August 1788). "For upwards of 23 minutes it blew with incredible fury; and had the wind not suddenly shifted to the $\mathrm{N}$ every vessel in the harbour must have been drove on shore" (The Independent Journal (NYC), Wednesday, 20 August 1788).

Upon arrival at NYC, Boose et al. [2001] estimate a $R_{\max }$ of $50 \mathrm{~km}$, a $V_{\max }$ of $51.4 \mathrm{~m} \mathrm{~s}^{-1}$ (a weak Category-3 hurricane), and storm track and timing data that imply a storm translation speed of $17.5 \mathrm{~m} \mathrm{~s}^{-1}$. The Boose storm track estimate suggests a fast storm translation speed of $17.5 \mathrm{~m} \mathrm{~s}^{-1}$ [Boose et al., 2003]. The Boose paper estimates storm sizes in categories of 50,75, and $100 \mathrm{~km}$, but the news accounts and debates about whether it was a squall or a hurricane [Ludlum, 1963] suggest it was smaller than the $50 \mathrm{~km}$ minimum scale allowed in the Boose study. Also, the extremely brief period of high winds has been used to infer that the 1788 hurricane was a small, fast-moving storm [Ludlum, 1963]. If we take 11:30 EST to be the time of maximum wind, 11:53 EST ("23 min" later) to be the time the eye began passing over NYC, and 12:00 EST ("about midday") to be time of the directional switch, then the storm center passed at about 11:57. A 27 min time with a storm traveling $\sim 63.5 \mathrm{~km} \mathrm{~h}^{-1}$ leads to an estimate of $29 \mathrm{~km}$ for the radius of maximum winds. We estimate with tide-only modeling that the high tide on 19 August 1788 at 09:30 EST would have been $+0.78 \mathrm{~m}$, and the peak water level of $2.9 \mathrm{~m}$ would have occurred $2.75 \mathrm{~h}$ after high tide, at 12:15 EST, when the tide was at $-0.1 \mathrm{~m} \mathrm{MSL}$. This contrasts with 1821, where the storm surge occurred at low tide.

Flood-driven damages of the storm in NYH included destruction of the Battery seawalls, many wharves, several bridges, and a filling in of many cellars on Lower Manhattan streets such as Front, Water and to a lesser extent Queen (now called Pearl Street) [Boose et al., 2003], similar to the 1821 TC. "It was full sea at 6 minutes past 11 A.M. but it still flowed until 12, when there was a rise of water of at least 5 feet higher than usual, which filled all the cellars in Front-Street, besides many in Water Queen-Streets, and on the NorthRiver [Hudson River]" (The Providence Gazette and Country Journal, Tuesday, 30 August 1788). Wind-driven damages from the roughly $50 \mathrm{~m} \mathrm{~s}^{-1}$ winds were also severe, with chimney and roof damage to many homes on Manhattan [Boose et al., 2003].

The 1788 hurricane's storm tide has previously been estimated as $3.0 \mathrm{~m}$ at NYH (error bars from 2.5 to $3.5 \mathrm{~m}$ ), based on the flooding of basements on Front and Water Streets and their present-day elevation [SCileppi and Donnelly, 2007], and multiple studies state or imply that the storm tide was lower than that of the 1821 TC in the region [Donnelly et al., 2001; Scileppi and Donnelly, 2007]. We interpret "... at least $5 \mathrm{ft}$ higher than usual" as meaning $5 \mathrm{ft}$ above spring high tide, meaning the "usual variability of water," not mean high 
water (again, the pre-1850 convention was to use spring tides when discussing a tidal datum) [see e.g., Sha-

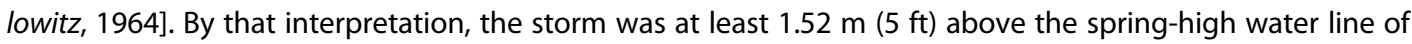
$1.0 \mathrm{~m}$, or, in other words, a storm tide of "at least" $2.5 \mathrm{~m}$. Based on the water levels and damages described above, it is clear that it was nearly as high a storm tide as the 1821 hurricane, giving a likely range from $2.5 \mathrm{~m}$ up to the 1821 high-end estimate of $3.3 \mathrm{~m}$.

Our final quantitative estimate of the observed 1788 storm tide comes from newspaper reports in September 1821, which state that the high water line for the 1821 event exceeded the previous high at a tidal mill by $0.10 \mathrm{~m}$ ("4 in.") [Kussman, 1957, p. 47]. No other known hurricane storm tide (e.g., 1805, 1815) came close to the 1788 event, according to news quotes from Boose et al. [2003], so the "previous high" appears to have been from 1788. Along with our 1821 estimate of $3.0 \mathrm{~m}$, we use this to finalize our estimate as $2.9 \mathrm{~m}$ (2.3-3.3 at $95 \%$ confidence) for the 1788 TC storm tide. We use a larger low-end uncertainty for both the 1788 and 1821 events to account for our observation that contemporary accounts (e.g., newspapers, diaries) often overestimate, but seldom underestimate, storm tide magnitudes (e.g., the 1893 event mentioned at the top of section 3 ). The resulting temporal-maximum storm surge estimate, differencing this estimated storm tide and the modeled tide, is $3.0 \mathrm{~m}$ (Table 2). Because mean sea level at the Battery was $0.56 \mathrm{~m}$ lower in 1788 than it was in 2012 [Kemp and Horton, 2013], the 1788 peak water elevation was about $1.05 \mathrm{~m}$ lower than Sandy in absolute terms.
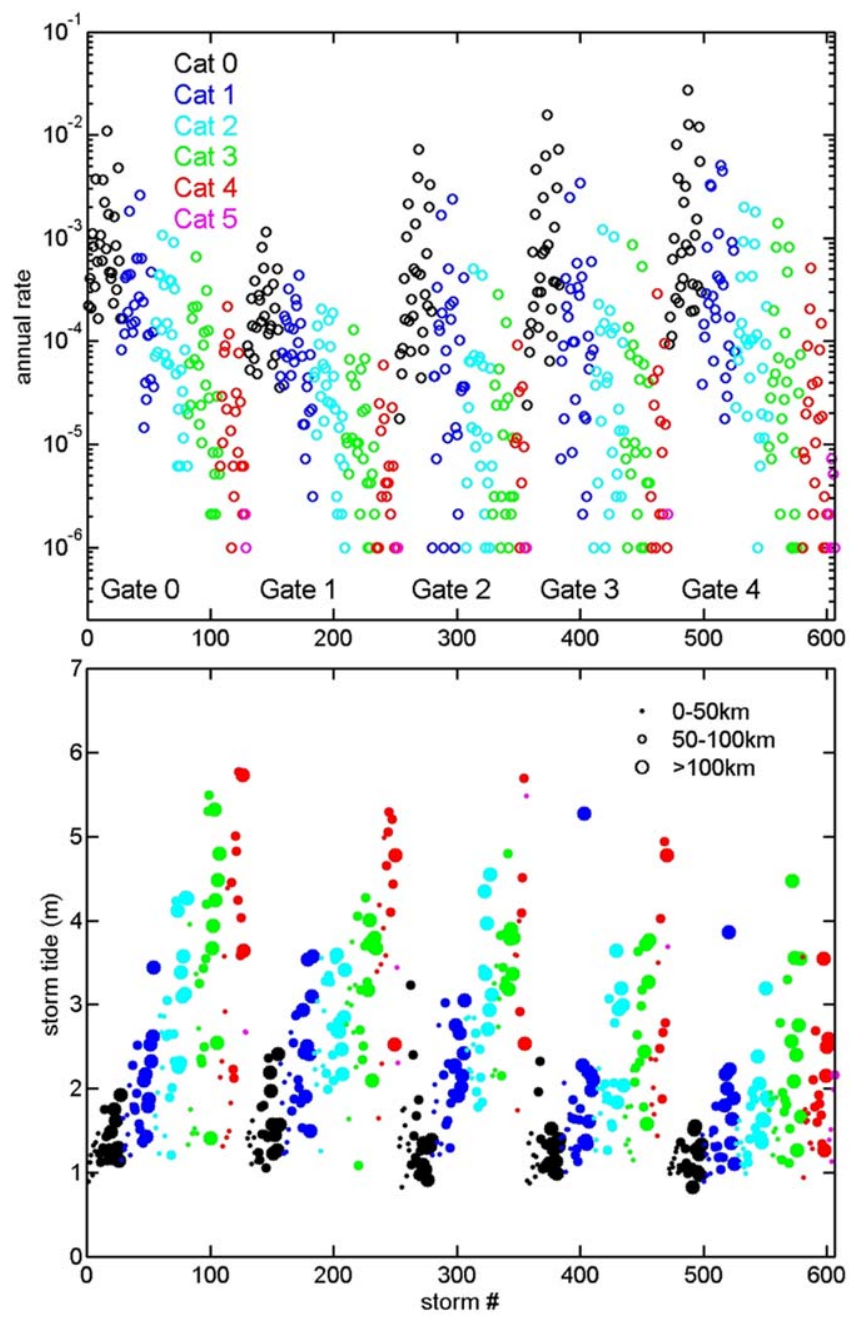

Figure 6. (top) Annual rates and (bottom) modeled storm tide for each of the 606 synthetic TCs. Colors indicate Saffir-Simpson category, and landfall gates are also shown ( 0 for southern New Jersey, moving clockwise to 4 for eastern Long Island; shown in Figure 2). (bottom) Storm size, an important determinant of storm tide.

\section{Results}

Before presenting results for the flood hazard posed to NYH by TCs and ETCs (section 4.3), we first show that our model reproduces historical events (section 4.2) and that our modeled TC storm climatology approach (described in section 2.1) produces landfall rates that are consistent with those estimated from a historical observation database (section 4.1).

\subsection{Tropical Cyclone Climatology and Landfall Return Period Validation}

The modeled annual rates, intensities, storm sizes, and storm tides of each of the 606 TC flavors are summarized in Figure 6 . The TCs are organized in order of the gate crossed, from 0 to 4 as defined in Figure 2. Rates of landfall of any TC through gates 0 through 4 are 0.058, 0.012, 0.035, 0.065, and 0.121 , respectively. Gate 4 is the most likely to be crossed by a TC in any given year, due to being a relatively long gate and being in line with the more common offshore storm tracks. While storms crossing gate 0 are half as likely as gate 4, they typically cause a higher storm tide because the largest observed winds are to the right of the storm track in the northern hemisphere (Figure 6b). Broken down by intensity, categories 0 through 5 occur 


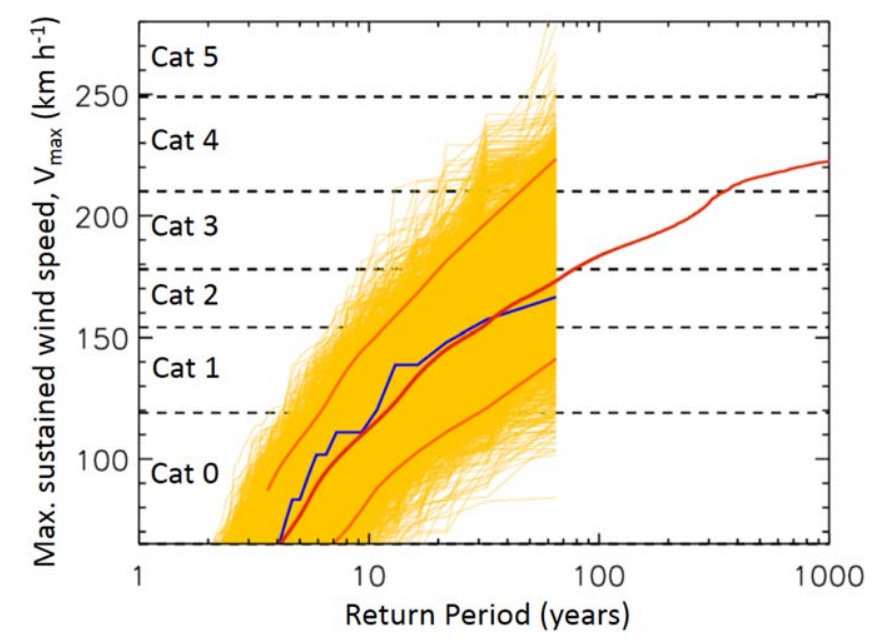

Figure 7. Historical evaluation of the statistical TC model. Shown are landfall wind speed exceedance curves for the greater New York Bight region (across all five landfall gates). Yellow curves are shown for each of the 15,625 simulations of the 64 year (1950-2013) period. The orange curves indicate the lower and upper bounds of the inner $95 \%$ across the simulations. The red curve is obtained by combining the simulations in series (i.e., a 1,000,000 year simulation). The blue curve is obtained directly from HURDAT landfalls. at annual rates of $0.205,0.0529,0.0200$, $0.00977,0.00294$, and 0.000025 , or return periods of $4.9,19,50,100,340$, and 40,000 years. Integrated over all events, there is between a $1 / 3$ and $1 / 4$ chance of a TC occurring in any given year (probability $=0.29$ ). Qualitatively, these return periods match with historical experience; for example, three Category-1 or higher TCs are believed to have struck the NYH area (gate 2 ) in the last 240 years (1788, 1821, and 1893), or once every 80 years, giving an observed probability similar to the 0.009 year $^{-1}$ return period we estimate.

The modeled probability of a TC passing any of our gates (Figure 6) is validated by comparing against the measured HURDAT database from 1950 to 2013 (Figure 7). The modeled probability (red line) of an event with a certain sustained wind speed fol-

lows historical observations (blue line) well. Both the modeled and measured curves are concave down, such that larger wind speed events have a sharply lower probability of occurrence in this area. Model landfall is unbiased, or consistent with historical landfall rates, to the extent that the observed return period curve falls inside the $95 \%$ confidence range of model-based return periods (orange lines), which is the case.

\subsection{Storm Tide Modeling Validations}

We next validate our modeling approach by comparing measured and simulated storm tides for ETCs (Figure 8). Modeled results show a small mean bias of $-0.03 \mathrm{~m}$ with an RMSE of $0.19 \mathrm{~m}$. This mean bias is sub-

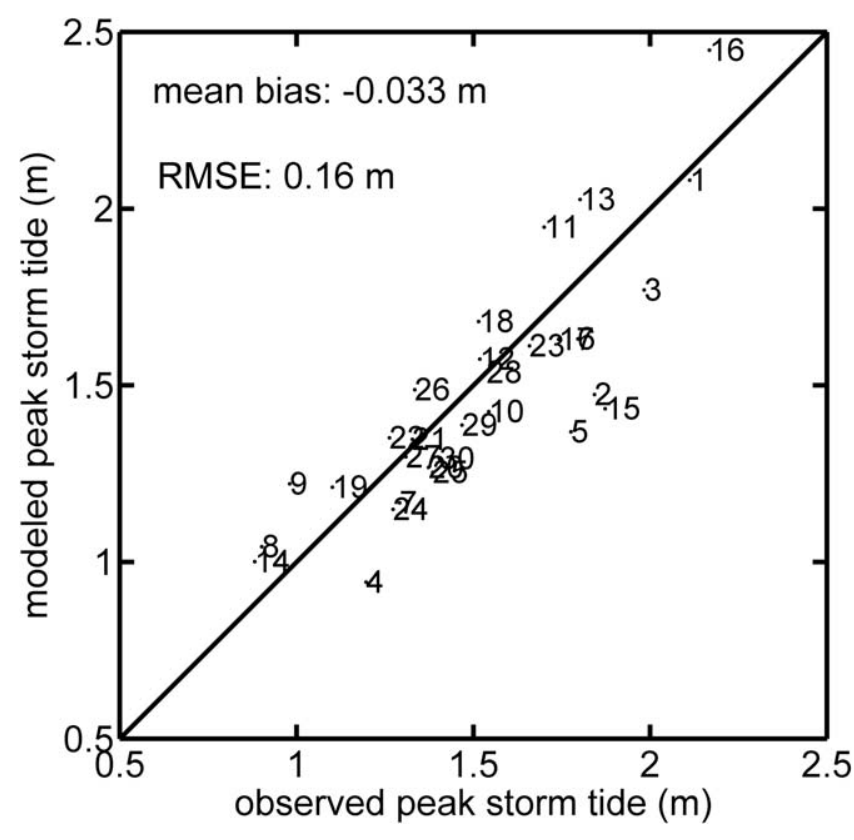

Figure 8. Historical evaluation of the ETC coupled ocean-atmosphere model results for the Battery tide gauge (NYH), including mean bias and RMSE. Numbering of data points (storm events) is given in Table 1. tracted from all modeled ETC storm tides before use in the statistical analysis. After bias correction, only four events have an error on the peak storm tide of greater than $0.30 \mathrm{~m}$, the 19610413, 19660123, 19911031 , and 19921211 storms, at $0.34,0.37,0.41$, and $-0.31 \mathrm{~m}$, respectively.

A close look at Figure 8 shows that the 1950 ETC model result (storm \#1) is nearly identical to the observed historical values. The 1950 ETC simulation was initially found to substantially overestimate the observed storm tide by $1.2 \mathrm{~m}(58 \%)$. This was not likely a problem with the sECOM model; we also performed simulations with the same 1950 meteorological reanalysis data using the model ADCIRC in unpublished work related to a separate study [Orton et al., 2015a], and 


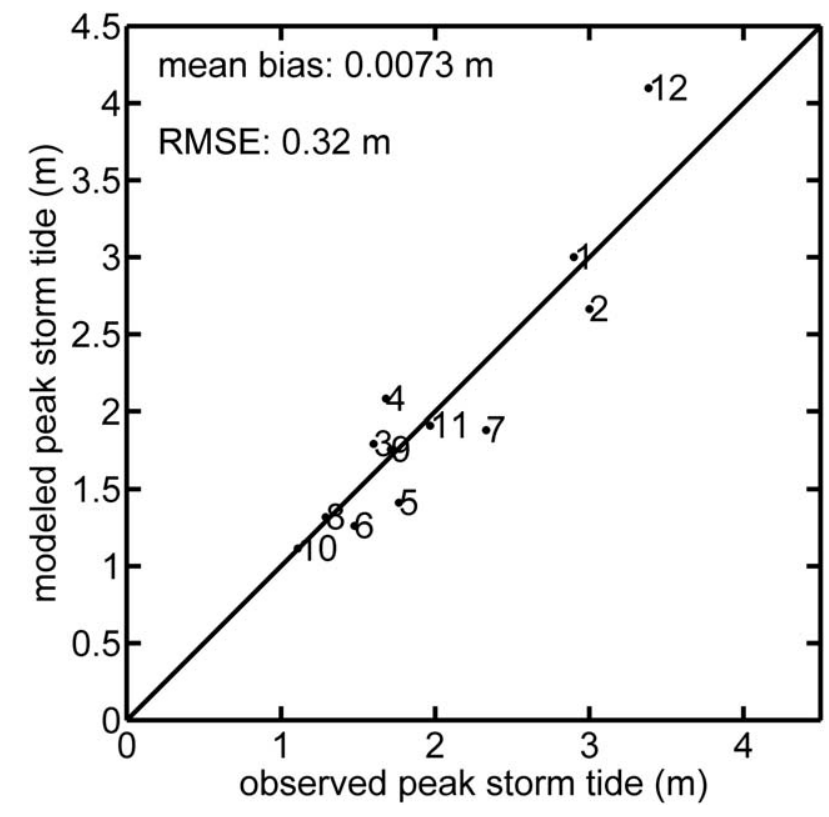

Figure 9. Historical evaluation of the TC coupled ocean-atmosphere modeling results for the Battery tide gauge (NYH), including bias and RMSE. Storm numbers are shown in Table 2. Atmospheric forcing is based on simple parametric wind and pressure fields, not detailed data. found the same amount of overestimation. This strong overestimation, coupled with this event being easily the largest storm surge in the ETC storm set, together motivated a reduction of wind speed to create a model simulation that better represents the historical event. A wind reduction factor of 0.83 was found to create a near-perfect fit to the event's peak storm tide, as well as an RMSE of $0.16 \mathrm{~m}$ and mean bias of $-0.03 \mathrm{~m}$ for the storm tide time series. The justification for this adjustment is discussed in section 5.3. Due to this tuning of wind speed, this storm's results are not included in the statistics shown in Figure 8.

A set of 12 historical events (Table 2) was selected for validation of the TC atmosphere-ocean simulation methods, including five large surge events from 1.7 to $3.4 \mathrm{~m}$ (1788, 1821, and 2012 Sandy, 1960 Gloria, and 1985 Donna) and another seven that are in the more common $1.0-1.3 \mathrm{~m}$ surge range. The TC validation

data are built by comparing peak storm tide $\left(\eta_{\text {max }}\right)$ model results to observations (Figure 9). For the 1788 and 1821 hurricanes, this is the maximum model result in 10 min output time series, as the observation is a high water mark. For the other storms, it is the maximum model result in decimated output time series, as we use the hourly historical observation time series from the Battery [NOAA, 2015] or Fort Hamilton, two measurement stations in NYH [Talke et al., 2014]. To emulate the methods used for the synthetic TCs, the wind and pressure for historical TCs were modeled using methods summarized in section 2.1, with data at 6-hourly intervals.

Parameters for validation storms are from the HURDAT database [NOAA-NHC-HRD, 2015], Extended HURDAT [Demuth et al., 2006], the recent FEMA study [FEMA, 2014b], and for the oldest storms, Boose et al. [2003]. The 1788 storm simulation, however, uses an $R_{\max }$ of $29 \mathrm{~km}$, as estimated in the prior section, due to the strong

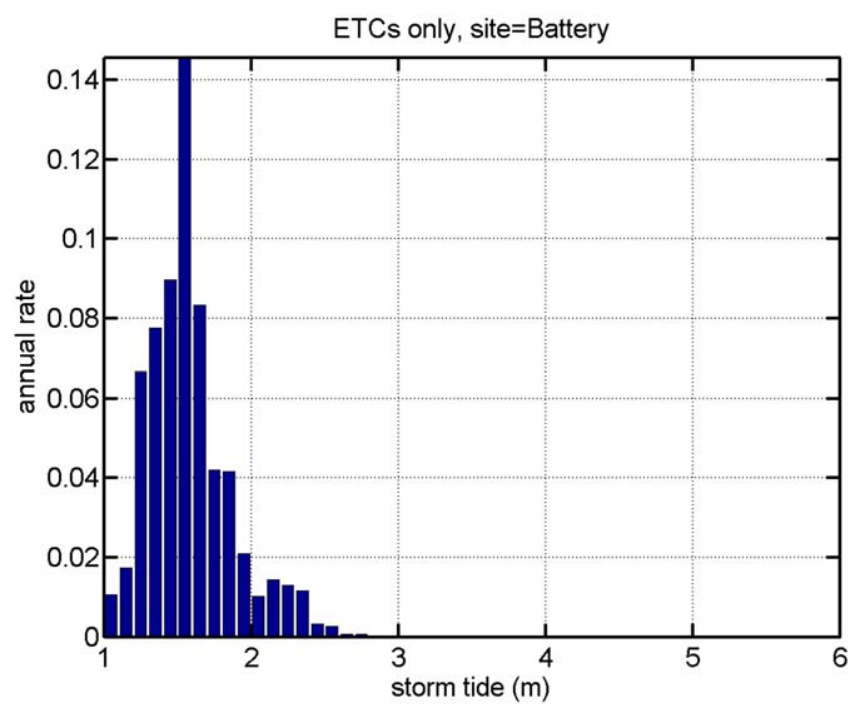

Figure 10. Annual rate distribution for modeled ETC storm tides. evidence for it being a smaller storm than the minimum in the Boose study. Pressure time series for the 1788, 1821, and 1893 storms are from equation (3), with central pressures around the time of passage at NYH of 952, 952, and 976 mbar, respectively.

The model mean bias for the TC hindcasts using parametric forcing is below $1 \mathrm{~cm}$ and root-mean-square error (RMSE) is $0.32 \mathrm{~m}$ (Figure 9). Hurricane Sandy's peak storm tide is overestimated by $0.71 \mathrm{~m}$, whereas a few other storms are underestimated by 0.34-0.46 m (1944, 1960, and 1821). However, a majority of the storms are simulated very accurately, within $0.20 \mathrm{~m}$ (1788, 1893, 1954, 1976, 1985, 1999, and 2011). The 1788 modeled 


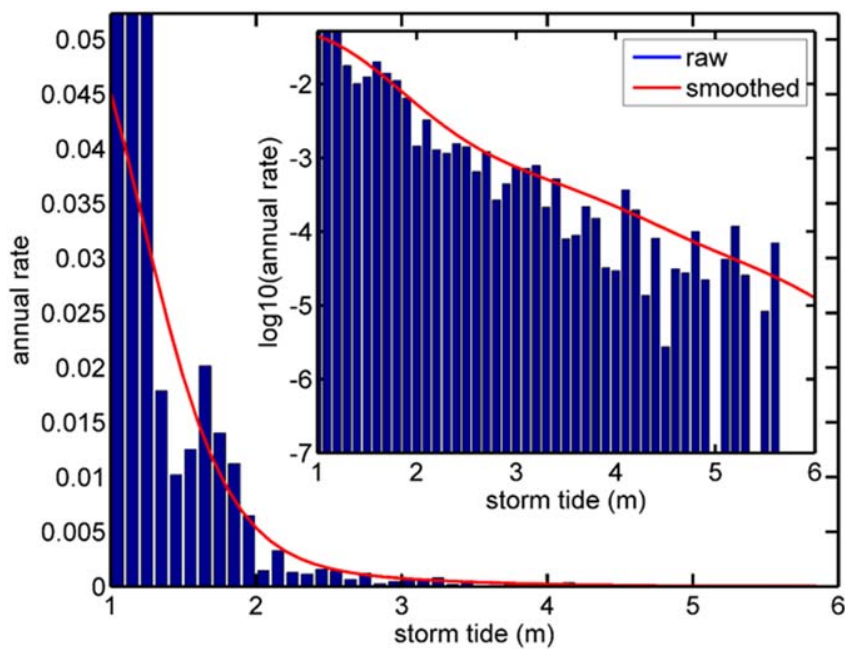

Figure 11. Annual rate distribution for modeled TCs (blue), also with the distribution as smoothed to account for the random tide and storm variations (red). The inset panel shows a logarithmic $y$ axis, to show the data in the long tail. storm tide of $2.95 \mathrm{~m}$ was $0.05 \mathrm{~m}$ higher than our archival estimate, and the 1821 modeled storm tide of 2.66 was $0.34 \mathrm{~m}$ lower the archival estimate. The 1821 TC meteorology is highly uncertain and it is not surprising that the storm tide modeling error would be large. Sandy was a hybrid ETC/TC before landfall, and therefore simplified parametric methods may not accurately represent the event physics; in fact, the modeled wind speed peak was far too high (29\%) and RMS error was also high $(5.6 \mathrm{~m}$ $\mathrm{s}^{-1}$ ) in New York Bight, compared with observations. The large overestimation of the Sandy storm tide can be explained largely by these excessive wind speeds, as sECOM runs with an accurate meteorological reanalysis

have lower wind speeds and give very accurate results [Orton et al., 2015b]. This is likely due to Sandy's being a hybrid storm; in looking at other recent TCs (e.g., Gloria, Irene) the parametric wind modeling is much more accurate (wind speed RMS errors of 2.8 and $3.5 \mathrm{~m} \mathrm{~s}^{-1}$, respectively). These considerations show that the hydrodynamic model is working well and suggest that though individual events may be overestimated or underestimated with a parametric approach, an ensemble with a sufficient number of events will yield unbiased estimates of storm tide probabilities.

\subsection{Annual Rate Distributions and Flood Exceedance Curves}

Annual rate distributions for ETCS and TCs are shown in Figures 10 and 11 and show a strong contrast in distribution shapes. The annual rate distribution for ETCs has a short tail, with the highest ETC storm tide at $2.67 \mathrm{~m}$. The $1950 \mathrm{ETC}$ is an important storm, due to its largest observed ETC storm surge $(2.41 \mathrm{~m})$, and its 50 simulated events with random tides have a spread from 2.00 to $2.67 \mathrm{~m}$. The annual rate distribution for TCs

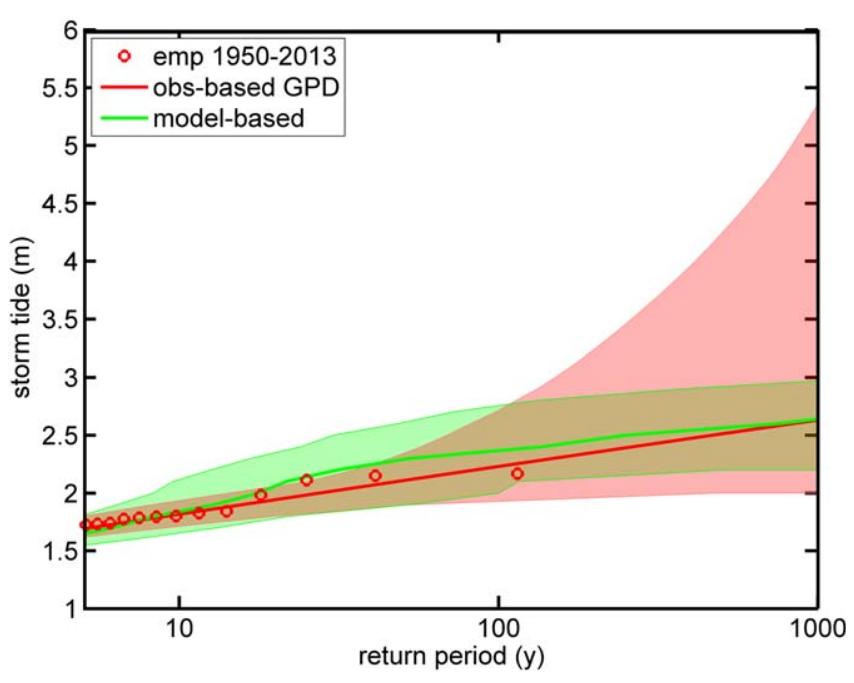

Figure 12. Results_ETC flood exceedance curve versus the 1950-2013 observation-based Generalized Pareto Distribution (GPD) assessment, both with shaded $95 \%$ confidence ranges. Open circles are empirically estimated return levels for specific events, with the highest point (the nor'easter on 11 December 1992) appearing at a return period of 115 years.
(Figure 11) and the smoothed version (explained in section 2.5) are both very long tailed, with low-rate events stretching out to the highest value of $5.77 \mathrm{~m}$ (a 0.000077 annual rate). Many storms represent the tail of the distribution, with 127 storm tide events above $3 \mathrm{~m}$, and 12 events above $5 \mathrm{~m}$.

Storm tide exceedance curves with 95\% uncertainty shading are shown for ETCs and TCs in Figures 12 and 13. The results show 100 year storm tides of $2.28 \mathrm{~m}$ (1.88-2.65) for ETCs, and $2.65 \mathrm{~m}$ (2.34-2.98 within 95\% uncertainty) for TCs. The uncertainty for the ETC flood exceedance curve is slightly larger due to the reliance on a small number of historical events over a 60 year period, and is quantified with the bootstrap resampling of these events in the Monte Carlo uncertainty analysis. 


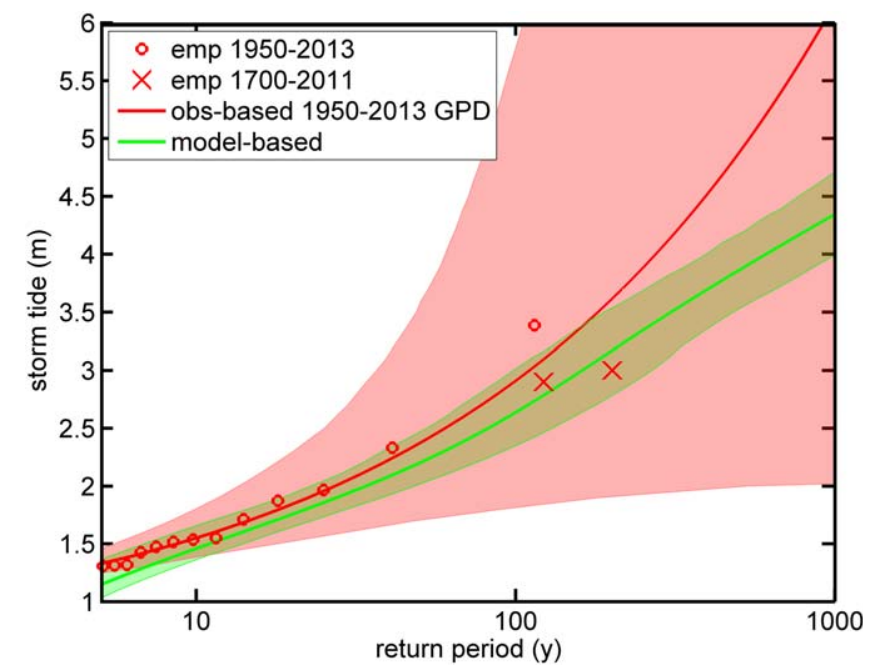

Figure 13. Results-TC flood exceedance curve versus a 1950-2013 observationbased GPD assessment, both with shaded $95 \%$ confidence ranges. Empirical points ("emp") from 1950 to 2013 and 1700 to 2011 are also plotted. The latter shows empirical return periods for the 1788 and 1821 hurricanes, computed using the longer period of 314 years (up to 2013) because we know these were the second and third highest events since 1700 .

Figure 14. The results of the combined assessment show 10,100,1000, and 10,000 year return period events of $1.94 \mathrm{~m}$ (1.78-2.14 at 95\% confidence), $2.70 \mathrm{~m}$ (2.51-2.92), $4.35 \mathrm{~m}$ (4.11-4.65), and $5.77 \mathrm{~m}$ (5.37-6.37), respectively. The storm tide hazard for shorter return periods is produced primarily by ETCs, while the risk of larger events with 100 year return periods or longer is almost exclusively driven by hurricanes.

\section{Discussion}

It is imperative that model-based flood hazard assessments have rigorous model validation, together with a verification that final flood exceedance curve results are not inconsistent with observation-based assess-

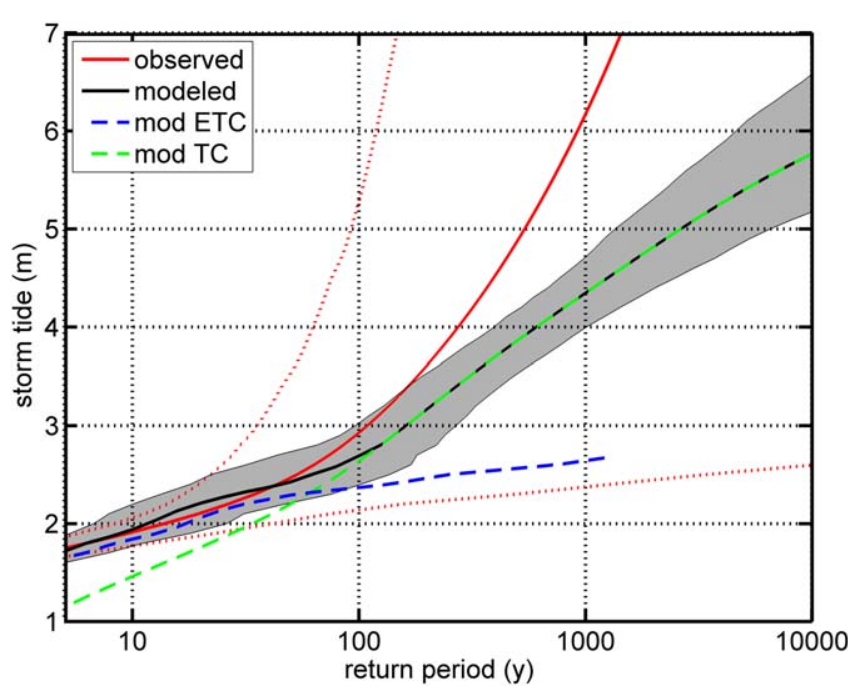

Figure 14. Model-based and observation-based flood exceedance curves for $\mathrm{NYH}$ combining TC and ETC curves from the prior two figures. The $95 \%$ confidence intervals are shown for the combined observed curve (red dotted lines) and modeled curve (grey shading). Storm tide is water level above mean sea level (MSL), and the model-based 100 year storm tide is $2.70 \mathrm{~m}$, or $2.64 \mathrm{~m}$ NAVD 88 when added on MSL 1983-2001. ments. Our TC and ETC flood exceedance curves are consistent with historical data, to the extent that our curves fall within the uncertainty of empirical return periods and observation-based GPD curves (Figures 12 and 13). The ETC flood hazard at $\mathrm{NYH}$ is relatively well constrained, with a $95 \%$ confidence range for the 100 year storm tide from 1.90-2.35 m, and our curve and uncertainty overlap. Our TC assessment results are also consistent with the observations, though the observation-based uncertainties grow larger with higher return periods, making it easier to achieve "consistency" between the observation-based and model-based curves. As such, this type of comparison is a more useful evaluation or validation for shorter return periods, but less useful, and not a powerful validation for longer return periods greater 
than the length of the observational record. Moreover, cases can arise where the observational record is short and lacks any extreme surge events, resulting in a lack of consistency with the model-based assessment. It may be necessary in these cases to use news reports (e.g., the 1788 and 1821 storm in this study) or paleorecords to better characterize the historical assessment of the flood hazard [Lin et al., 2014].

The observational and model-based results also demonstrate the importance of separately evaluating TCs and ETCs, for locations where both influence flooding at the return periods of interest. Flood return period curves for ETCS and TCS at this location have sharply different slopes, due to their differing meteorology. One primary inflection point is visible in the modeled flood exceedance curve (Figure 14). The lower return periods, up to a return period of about 100 years, have a concave shape, due to the switchover from ETC to TC dominance. The higher return periods above 100 years have a convex appearance. As a result, flood hazard assessments must treat the storm types separately in validation and return period computations. Fitting a single probability distribution to a combined storm tide data set with this inflection would lead to a poor representation of the flood hazard.

Physically, the convex shape of the flood exceedance curve at high return periods is likely a direct result of the convex shape of the TC wind speed exceedance curve (Figure 7). The latter is an expected result of TCs traveling northward into the mid-latitudes and encountering declining sea surface temperatures, leading to declining intensity and a lower probability of the strongest TCs [Emanuel, 2000]. The convex TC flood exceedance curve at high return periods is also likely a result of negative feedbacks on storm tide, such as wind drag saturation, tide-surge interaction, and oceanic mixing of cold subsurface water, which can both weaken storms and reduce wind stress. However, extratropical transition is only coarsely captured in our assessment through the parametric TC variables, for example the increase in TC size with latitude. Thus, uncertainty in our results for longer return periods is likely underestimated. The concave shape of the observation-based flood exceedance curve in Figures 13 and 14 leads to higher storm tides at long return periods than the model-based curve. This is at least partially a result of including Sandy in a GPD analysis of only a 64 year record (1950-2013; in Figure 13), whereas we know it was the highest event in over 314 years.

Results clearly demonstrate that ETCs dominate relatively short return period storm tides which occur every 5-10 years, while TCs drive risk for the 100 year and larger storms tides. The crossover return period for the TC and ETC curves is at 60 years (Figure 14); both storms have a 1/60 annual probability of producing a $2.3 \mathrm{~m}$ storm tide. This means that a 30 year storm tide (2/60 annual chance) is equally likely to be caused by a TC as an ETC (uncertainty from 10 to 91 years at the $95 \%$ level, sampling from the Monte Carlo analysis results). This result contrasts with the FEMA [2014b] study, where results show ETCs driving the flood level for all return periods at NYH.

Other recent studies have found substantially different exceedance curves at $\mathrm{NYH}$, as highlighted in section 1. The 100 year storm tide at NYH has had estimates ranging from $2.44 \mathrm{~m}$ [Zervas, 2013] to $3.50 \mathrm{~m}$ [FEMA, 2014b]. Our result of $2.70 \mathrm{~m}$ falls between these studies and is within the $95 \%$ confidence range of NOAA's historical-data-based estimate $(2.19-2.93 \mathrm{~m})$ [Zervas, 2013] and our own historical-data-based estimate (Fig-

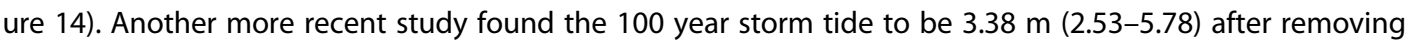
their 2013 mean sea level offset [Lopeman et al., 2015]. Our model-based 10 year return period storm tide of $1.94 \mathrm{~m}$ (1.78-2.14 at $95 \%$ confidence) is within our observation-based range (1.78-2.03 $\mathrm{m}$ ) and fairly central in the range of most prior studies, comparing well to the Talke et al. [2014] result of $1.91 \mathrm{~m}$, the Lopeman et al. [2015] result of $1.99 \mathrm{~m}$ (1.89-2.13), and the NOAA result of 1.85 (1.77-1.96) [Zervas, 2013]. An outlier is the FEMA 10 year storm tide [FEMA, 2014b] result of $2.19 \mathrm{~m}$. Comparing longer return period events, only estimated in the Lin et al. [2012] TC study, our results of $4.35 \mathrm{~m} \mathrm{(4.11-4.65)}$ and $5.77 \mathrm{~m}$ (5.37-6.37) for the 1000 year and 10,000 year storm tides are larger than their results of 3.55 and $4.75 \mathrm{~m}$, respectively. The return period for a Hurricane Sandy level storm tide of $3.38 \mathrm{~m}$ in our assessment is 260 years (170-420 at 95\% confidence), in comparison to values that can be inferred from other studies as $\sim 100$ years [FEMA, 2014b; Lopeman et al., 2015], 250 years [Lin et al., 2012], and 1500 years [Sweet et al., 2013; Zervas, 2013].

\subsection{Sensitivity of Results to Hydrodynamic Model Physics}

Differences between our study and the other recent studies are discussed separately for TCs and ETCS below, but hydrodynamic modeling differences used for both type of storm may be partially responsible. A major difference distinguishing factor between studies in this region is the sea surface drag coefficient 
parameterization and its ceiling (section 2.3). We use a wave-slope sensitive parameterization [Taylor and Yelland, 2001], and find that the best fit ceiling value is 0.0035 , for fitting historical TC storm tides (measured with RMS error) with our simplified wind fields. Prior studies in the area have used the Garratt [1977] parameterization with ceilings of 0.0025 [Lin et al., 2012], 0.0030 [Wang et al., 2014], 0.0035 [FEMA, 2014b], and with no ceiling [Colle et al., 2015]. Misalignment of wind and swell can be a source of higher drag [e.g., Holthuijsen et al., 2012], but these processes are not well understood, and other factors such as storm translation speed are important [e.g., Reichl et al., 2014] and not represented by existing wind speed-based drag parameterizations. In our study region of the funnel-shaped coastline of New York Bight, this saturation ceiling could often be higher than straight coastlines due to misalignment. This can arise due to wave refraction bending waves shoreward on the broad continental shelf, or due to the fact that the winds that drive storm surge into the apex of the Bight are often not from the southeast (they are from the east or northeast).

A recent study separated surge, tide and sea level rise, computed statistics and used data from a Monte Carlo simulation to create hazard statistics as the sum of the three components, and found a 100 year flood level of $3.38 \mathrm{~m}$, greater than our storm tide estimate by $0.67 \mathrm{~m}$ [Lopeman et al., 2015]. We quantify the possible bias here from omission of tide-surge interactions in the storm tide hazard, by repeating our assessment with sums of randomly shuffled modeled tide time series plus modeled surge time series, to emulate their use of a sum of observed storm surge and astronomical tides. The aforementioned "modeled surge time series" is computed as the modeled storm tide minus the modeled tide-only time series, emulating how their observations of surge are computed. This tide plus surge result is $0.25 \mathrm{~m}$ higher for the 100 year TC storm tide, is $0.23 \mathrm{~m}$ higher for the 100 year ETC storm tide, and is $0.30 \mathrm{~m}$ higher for the final combined 100 year storm tide. This result suggests that the omission of tide-surge interaction in the Lopeman et al. [2015] paper would lead to a high-bias in their results of about $0.30 \mathrm{~m}$ at the Battery, or $10 \%$. If one subtracts this from their result, the result is a 100 year storm tide of $3.08 \mathrm{~m}$, only $0.38 \mathrm{~m}$ above ours, a much smaller discrepancy.

Different hydrodynamic models include different processes related to waves, though impacts on water elevation are likely small in deep water harbor regions like $\mathrm{NYH}$. Our modeling omits wave radiation stress and resulting wave setup, which was recently shown to increase NYH storm tides by a $1.5 \%$ on average [Lin et al., 2012]. This low bias may be counteracted in our modeling through other factors, such as a possible high-bias in wind stress (e.g., due to the choice of drag coefficient parameterization). Two-dimensional ADCIRC and SLOSH modeling used in prior studies, however, neglects the contribution of wave orbital velocities to bed stress [Grant and Madsen, 1979], which we include in our three-dimensional modeling. In conclusion, a detailed study of the role these wave-related processes play in the modeling of storm tides is warranted.

A final way that our approach differs from prior NY region studies is that it leverages an existing ocean forecast system, and thus includes many more subtle details that are often treated as negligible in coastal flood hazard assessments. This includes incorporation of the seasonality of sea level and air temperature, the latter of which impacts air density and therefore wind stress. The former has an impact from -10 to $+7 \mathrm{~cm}$, and the latter $\pm \sim 5 \%$ on storm tides for individual storms in this region, perhaps most importantly impacting the difference between warm-season TC storm tide and cool-season ETC storm tides. These seasonally varying variables act in opposition and will to some extent offset one another, but were simple to include in the assessment because of the availability of codes and data sets from the operational forecast system.

\subsection{The TC Storm Tide Hazard}

The results of our TC assessment give a 100 year TC storm tide of $2.64 \mathrm{~m}$ (2.45-2.87 95\% confidence interval), relative to recent studies results of $2.03 \mathrm{~m}$ [Lin et al., 2012] and $2.75 \mathrm{~m}$ [FEMA, 2014b]. The former study simulated TCs within the NCEP/NCAR reanalysis-based climate conditions of 1981-2000, and does not account for extratropical transition effects, which may account for the lower result (see discussion in Lin et al. 2016). Our study also differs from these two studies in its statistical TC modeling method, as well as its methods for estimating TC wind and pressure fields. The TC meteorology used in our study is simplistic, and we have observed it to give inaccurate winds for Hurricane Sandy, but generally good agreement with observations for a few other recent storms (section 4.2). However, the validation of the model results with historic storm tides demonstrates the results are reasonable. 
One difference in the TC storm climatology is clear in Figure 2, because we have left-hand turn storms that were not included in storm sets of the FEMA [2014b] study. In our study, even though the westward-directed storms are rare, they do occur and tend to cause the largest storm tides. By contrast, while Lin et al. $[2010,2012]$ also have storms that head westward in this region, their largest storm tides were caused by storms moving northward. It would be useful to have a detailed inter-comparison study among TC hazard models for the region to elucidate the reasons for these differences.

Care must be taken with our method of building the TC storm subset, choosing landfall gates that capture all storms which are important for the combined flood hazard at NYH. The gates are chosen to capture all possible TC events with surges over $1.25 \mathrm{~m}$ (e.g., Figure 2a), capable of causing storm tides exceeding $\sim 2 \mathrm{~m}$. Sensitivity experiments were used to evaluate the importance of passing inland storms, storms that make landfall to the east of Long Island, and storms that never make landfall but pass within $2 R_{\max }$ of $\mathrm{NYH}$. The combined impact on the 100 year storm tide of using three more gates to account for these TCs is an increase of $1 \mathrm{~cm}$, as inland storms are too weak to cause large surges and offshore storms cause a wind direction that is unable to cause a large surge for NYH. Inclusion of this broader set of TCs would moderately increase the 5 and 10 year TC flood hazard, which tails off below the historically based estimates at these low return periods (Figure 13). However, our final results do not use these TCs, because this region of the curve is not important for the total storm tide hazard (below a $1 \mathrm{~cm}$ change); ETCs completely dominate the 5 and 10 year storm tides.

It is not surprising that our study and the FEMA study, which capped the sea surface drag coefficient $\left(C_{D}\right)$ at 0.0035 , found larger TC storm tides than the Lin et al. [2010, 2012] studies, which capped $C_{D}$ at 0.0025 . We found the cap of 0.0035 gave us the best fit to historical events (see section 2.3), but this does not mean it is the "correct" drag coefficient cap; it simply gives us the best results in the context of our coupled oceanwave modeling and simplified wind and pressure fields. Nevertheless, TC assessments might collapse toward closer agreement if the same drag coefficient methods were utilized. This underscores the importance of coupled ocean-atmosphere validation and possible model tuning using historical events, as was advocated for by Cardone and Cox [2009].

\subsection{The ETC Storm Tide Hazard}

The results of our ETC assessment give a 100 year ETC storm tide of $2.38 \mathrm{~m}$ (2.07-2.75 95\% confidence range), relative to the FEMA study result of $3.23 \mathrm{~m}$ [FEMA, 2014b] and our observation-based (GPD) assessment of $2.22 \mathrm{~m}$ (1.95-2.72). Our model-based and observation-based estimates are in general agreement, within uncertainty, and both are substantially lower than the FEMA result. Our observation-based estimate is lower than our model-based estimate because the largest historical ETC storm surge (19501125) peaked at low tide, giving a storm tide of $2.12 \mathrm{~m}$. The modeled 19501125 ETC events occur at 50 random tide phases, giving storm tides from 2.07 to $2.71 \mathrm{~m}$, accounting for a wider range of possible floods.

The difference in ETC results between our study and the FEMA study are the main reason for the differences between the studies' combined flood exceedance curves, considering that the estimates of the 100 year TC storm tide are nearly the same. Our study differs from that study in the wind speed factors used, discussed below, and in our scaling up of 11 storm annual rates to make up for specific missing top 30 storm surge events at NYH (section 2.2). The impact of scaling up storm rates for the missing storms is an increase from 1.79 to $1.86 \mathrm{~m}$ for the 10 year storm tide, and a small decrease from 2.29 to $2.27 \mathrm{~m}$ for the 100 year storm tide. A goal here is to accurately capture storm tides at short return periods down to 5 years, so the scaleups appear useful.

The FEMA [2014b] study multiplied the reanalysis wind speeds for all storms by 1.04 , whereas we keep the winds unmodified except for the 1950 storm, where we lower them by $17 \%$ to accurately fit the hindcast event (section 4.2). We suspect the need for downscaling of wind speed for this one storm either results from errors in the storm's wind speed estimates due to the absence of measurements over the ocean for that storm, or from error in our estimated drag coefficient ceiling value of 0.0035 . On the latter possibility, this was a rare "southeaster" storm where winds were blowing steadily at $25-30 \mathrm{~m} \mathrm{~s}^{-1}$ over a large fetch (Figure 4) and in the same direction that the wave field was traveling (toward the west-northwest); recent work has shown that the drag coefficient cap can be much lower for this scenario [Holthuijsen et al., 2012]. Our wave modeling results in New York Bight show a mean wave-wind misalignment of only $5^{\circ}$ for the 
1950 ETC, blowing in the direction of wave propagation, in comparison to $95^{\circ}$ for Hurricane Sandy (average for 28-29 October 2012), blowing along the wave crests.

The FEMA study storm set was completed in 2011 and only considered ETCs from 1950 to 2009, but our study has the benefit of a wealth of data that has become available since Hurricane Sandy in 2012 [e.g., Talke et al., 2014]. We can look at a broader time period to evaluate our result, and there appear to have been no ETC storm tides over $2.2 \mathrm{~m}$ at least back to 1821 , indicating that their result of $3.23 \mathrm{~m}$ is very likely too high. Moreover, their study simulated only two random tide scenarios, but our 50 random tide scenario runs for the most intense storms shows ETC storm tides never reaching above $2.7 \mathrm{~m}$.

Our designation of hybrid storms that begin like Hurricane Sandy as TCs is important here, as moving these storms into the ETC category could change our interpretation of the historical data and our comparison to our model-based results. However, it makes the most sense to divide them in this way because ETCs of nontropical cyclone origin in this coastal region have historically never shown a peak sustained wind speed more than $35 \mathrm{~m} \mathrm{~s}^{-1}$ at $10 \mathrm{~m}$ above sea level [e.g., Cardone et al., 1996; Dolan and Davis, 1992], whereas the HURDAT database [Landsea et al., 2004] reveals that North Atlantic TCs have historically had a top wind speed of $85 \mathrm{~m} \mathrm{~s}^{-1}$. The dynamical differences between TCs/hybrids and ETCs further justifies separation into two statistical distributions and extreme value statistical analyses. Because of the rare, but possible, chance of such extreme wind speeds, TC and hybrid storm surges exhibit a "long-tailed" probability distribution, and the worst-case flood scenario for a TC/hybrid is much larger than for an ETC.

\subsection{Impacts of the $\mathbf{1 7 8 8}$ and $\mathbf{1 8 2 1}$ Hurricanes at New York City}

Understanding what occurred during the 1788 and 1821 hurricanes is highly valuable because they are the two largest known prior storm tide events prior to Sandy and also exhibited much stronger wind speeds that would cause severe damage and airborne debris. Our parametric modeling showed excellent agreement with our archival estimates for the 1788 event, but underestimated the 1821 estimates by 0.34 m (Figure 9). The mixed results are unsurprising, considering that the meteorology for both storms consists of simplified wind and pressure fields based on land-damage from wind [Boose et al., 2001], and is therefore only approximate.

Our archival research-based 1821 storm tide estimate of approximately $3.0 \mathrm{~m}$ (and storm surge of $3.4 \mathrm{~m}$ ) is a downgrade by $0.2 \mathrm{~m}$ from the widely cited Scileppi and Donnelly [2007] paper. Our model result for the storm tide, however, is only $2.66 \mathrm{~m}$. One possible explanation for this is inaccurate wind speed estimates; a prior recent study using SLOSH found a higher wind speed is needed, relative to the Boose et al. [2001] study estimate of $51.4 \mathrm{~m} \mathrm{~s}^{-1}$ at landfall, to fit a presumed (inaccurate by $+0.2 \mathrm{~m}$ ) storm surge of $3.6 \mathrm{~m}$, and the best fit came when maximum sustained wind speeds of $58 \mathrm{~m} \mathrm{~s}^{-1}$ [Brandon et al., 2014]. These results suggest that the Boose et al. [2001] wind speeds at sea for that storm may be too low. In a separate paper on nature-based flood protection, we used a peak wind speed of $58 \mathrm{~m} \mathrm{~s}^{-1}$, and obtained a storm tide peak of $2.95 \mathrm{~m}$ at NYH, much closer to the estimated observed value [Orton et al., 2015b].

One widely cited [Brandon et al., 2014; Coch, 1994; Redfield, 1831; Scileppi and Donnelly, 2007] and impressive factor with the 1821 storm tide in NYH was that the water rose 13 feet in $1 \mathrm{~h}$, based on a newspaper quote. The New Bedford Mercury quote read "In one hour during the [hurricane] of Monday evening, the water was forced into the East River 13 feet 4 inches [ $4.0 \mathrm{~m}$ ] above low water mark." [Boose et al., 2003]. The quote is important because such a rapid rise in one hour is extreme and would require high water velocities and likely lead to substantial erosion and possible undermining of infrastructure. The maximum water rise rate in NYH during Hurricane Sandy, for contrast, was only $0.7 \mathrm{~m} \mathrm{~h}^{-1}$.

Our historical reassessment shows that the $4 \mathrm{~m} \mathrm{~h}^{-1}$ rise rate for the $1821 \mathrm{TC}$ is unlikely to have occurred, in part because the water only rose $3.4 \mathrm{~m}$ total, but also because our modeling suggests this rise rate was improbable. Our most accurate 1821 hurricane storm tide simulation [Orton et al., 2015b] shows a maximum rise rate of $1.8 \mathrm{~m} \mathrm{~h}^{-1}$ for the storm tide, and our simulation of the smaller and faster 1788 hurricane shows a faster rise rate of $2.4 \mathrm{~m} \mathrm{~h}^{-1}$. More broadly, the fastest water rise rate for 2.5-3.5 $\mathrm{m} \mathrm{TC}$ storm tide events in our modeling is $2.4 \mathrm{~m} \mathrm{~h}^{-1}$ and the average is $0.8 \mathrm{~m} \mathrm{~h}^{-1}$.

A recent study of lagoonal sediment cores at New York City's Staten Island showed that the 1788 event had a much thinner and finer sand layer than the 1821 event [Brandon et al., 2014]. This same observation was made by Scileppi and Donnelly [2007], and they surmised that the smaller storm size explained the less 
prominent and sometimes missing sand overwash layer on Long Island. The maximum storm surge at NYH for the 1788 hurricane was only slightly smaller $(2.9 \mathrm{~m})$ than the 1821 storm tide $(3.0 \mathrm{~m})$, but the storm was of a smaller size (wind fetch), faster speed, and thus a shorter duration [Ludlum, 1963], likely resulting in smaller waves. Our model results show peak significant wave heights and wave periods in New York Bight's apex (NDBC Buoy 44065) for 1788 of $9.4 \mathrm{~m}$ with period $14.5 \mathrm{~s}$, whereas they are $13.5 \mathrm{~m}$ and $18.1 \mathrm{~s}$ for 1821 (versus observed values of $9.9 \mathrm{~m}$ and $16.0 \mathrm{~s}$ for Hurricane Sandy). These factors likely explain why the 1788 sediment layers were smaller, with finer sediments.

The 1788 hurricane storm tide estimate is lowered by $0.1 \mathrm{~m}$ relative to the recent Scileppi and Donnelly [2007] estimate, and uncertainty is also reduced due to the fact that multiple sources of the estimate now exist and are in approximate agreement-(1) the elevation over street level at Front and Water streets of lower Manhattan, because most cellars ended up filled with water, (2) a quantitative comparison of different storm tides at one tidal mill location (section 3.2), and (3) our model result of $3.0 \mathrm{~m}$. These all support our estimate of a storm tide of $2.9 \mathrm{~m}$, at $95 \%$ confidence.

As recently noted by Swiss Re [2014], the impacts of these storms went beyond flooding, as they were Category-3 hurricanes that passed over NYC. Sustained maximum wind speeds at elevation over the city were roughly $50 \mathrm{~m} \mathrm{~s}^{-1}$ (not at $10 \mathrm{~m}$ level, which is more complicated and landscape dependent). If a hurricane of this intensity were to strike the region today, damages would likely be even greater than those from Sandy and would come from both winds and flooding [Swiss Re, 2014]. Our data suggest that the likelihood of a Category-3 or stronger hurricane passing near NYC (over landfall gates 1, 2, or 3) and causing a $3 \mathrm{~m}$ storm tide or higher is $\sim 0.003$ year $^{-1}$. Similarly, the probability of any combination of wind speed and flood level can be analyzed using the data produced in our assessment.

\section{Summary and Conclusions}

In this paper, we have reported on methods and results for a model-based flood hazard assessment we have conducted for New York Harbor, a region where prior assessments have differed widely. The methods are novel and provide a new and important contribution to the science of coastal flood hazard assessment. The assessment separately includes the contribution of TCs (including hybrids) and ETCs to the flood hazard, separating them because they represent storm tide events with different physical limits controlled by wind speed. The TC storm set includes results from a statistical TC model that has diverse storms including ones that curve westward like Hurricane Sandy. Resulting flood exceedance curves for any type of storm tide (TC and ETC) show 10,100,1000, and 10,000 year return period events of 1.94, 2.70, 4.35, and $5.77 \mathrm{~m}$, respectively.

Our study is the most deeply validated study of storm tides for the region performed to date, and lays out a framework for conducting similar studies for other areas. The storm sets are demonstrated to be consistent with historical data, and our coupled ocean-atmosphere modeling is accurate when validated against 42 historical events. The resulting TC and ETC flood exceedance curve results are consistent with an observation-based assessment for recent decades, as well as the empirical data points that include the worst events in the 1700 s and 1800 s that came prior to the tide gauge era.

A reassessment of the 1821 and 1788 hurricane storm tides at NYH was also performed, due to the fact that these are believed to have been Category-3 hurricanes with similar storm tides to Hurricane Sandy. The 1821 storm tide is estimated to be $3.0 \mathrm{~m}$ (2.5-3.3 at 95\% confidence), $0.2 \mathrm{~m}$ lower than a prior recent estimate [Scileppi and Donnelly, 2007]. The 1788 storm tide is estimated to be $2.9 \mathrm{~m}$ (2.3-3.3). The downgrade and reductions in uncertainty allow for the conclusion that the storm tides were lower than Sandy, and a resulting conclusion of this work is that Hurricane Sandy's storm tide at NYH was the largest at least as far back as 1700 .

More research is needed to ensure we can both account for the large variety of storms, and also accurately capture the atmospheric and oceanic physics of these extreme storms, to reduce this uncertainty and the differences between studies. Hybrids are a rare but highly impactful type of storm which needs further study, as do extratropical cyclones and their sources of energy that can lead to hurricane strength winds (e.g., latent heat). The coupling between atmosphere and ocean through wind stress and sea surface drag coefficient is a particularly important area requiring study for New York Bight, where winds and waves are often misaligned during storms due to the coastal geometry. 
The assessment framework is useful for other purposes beyond estimation of the present-day flood hazard, including sea level rise and climate change impacts on flooding. The framework and models are also useful for performing adaptation quantification studies where the model is manipulated to emulate structural or natural flood protection efforts that are happening rapidly after Hurricane Sandy. Funded projects are currently addressing both needs, using the data for studies of the Hudson River and Jamaica Bay, New York City (e.g., http://AdaptMap.info), and will be summarized in future publications.

\section{Acknowledgments}

Work by P.O., A.B., N.G., and S.V. was funded by the NASA Centers call for support of the National Climate Assessment (Hall, $\mathrm{Pl}$; agreements NNX12AI28G and NNX15AD61G), NASA's Research Opportunities in Space and Earth Science ROSES-2012 (grant NNX14AD48G), and NOAA's Regional Integrated Sciences and Assessments (RISA) program (award NA10OAR4310212). Work by T.H. was also funded by the NASA projects listed above. Work by S.T. was funded by the U.S. Army Corps of Engineers (award W1927N-14-2-0015).

Supercomputer resources were utilized under a grant of computer time from the City University of New York High Performance Computing Center under NSF grants CNS-0855217, CNS0958379, and ACl-1126113. This publication utilizes meteorological reanalyses constructed in part using data from NASA satellites/instruments, QuikSCAT, NSCAT and TOPEX/ POSEIDON, in some cases processed and made available by NASA's Jet Propulsion Laboratory. The model data, compiled NOAA water elevation observations, and Matlab codes necessary to reproduce the study are available at http://personal.stevens. edu/ porton/Orton_etal_JGR16.zip.

\section{References}

Aerts, J., W. W. Botzen, K. Emanuel, N. Lin, H. de Moel, and E. O. Michel-Kerjan (2014), Evaluating flood resilience strategies for coastal megacities, Science, 344(6183), 473-475.

Blake, E. S., T. B. Kimberlain, R. J. Berg, J. P. Cangialosi, and J. L. Beven (2013), Tropical Cyclone Report: Hurricane Sandy (AL182012), Natl. Hurricane Cent., Miami, Fla.

Blumberg, A. F., L. A. Khan, and J. St John (1999), Three-dimensional hydrodynamic model of New York Harbor region, J. Hydraul. Eng., 125(8), 799-816.

Boose, E. R., K. E. Chamberlin, and D. R. Foster (2001), Landscape and regional impacts of hurricanes in New England, Ecol. Monogr., 71(1), 27-48.

Boose, E. R., D. R. Foster, and K. E. Chamberlin (2003), Harvard Forest Data Archive, HF011: Landscape and Regional Impacts of Hurricanes in New England 1620-1997. [Available at http://harvardforest.fas.harvard.edu:8080/exist/apps/datasets/showData.html?id=hf011.]

Botts, H., W. Du, T. Jeffery, S. Kolk, Z. Pennycook, and L. Suhr (2013), CoreLogic Storm Surge Report 2013, 44 pp., CoreLogic, Irvine, Calif.

Brandon, C. M., J. D. Woodruff, J. P. Donnelly, and R. M. Sullivan (2014), How unique was Hurricane Sandy? Sedimentary reconstructions of extreme flooding from New York Harbor, Sci. Rep., 4, doi:10.1038/srep07366.

Bretschneider, C. (1972), A non-dimensional stationary hurricane wave model, Proc. Offshore Technol. Conf., 1, 51-68.

Cardone, V., and A. Cox (2009), Tropical cyclone wind field forcing for surge models: Critical issues and sensitivities, Nat. Hazards, 51(1), 29-47.

Cardone, V., R. Jensen, D. Resio, V. Swail, and A. Cox (1996), Evaluation of contemporary ocean wave models in rare extreme events: The "Halloween Storm" of October 1991 and the "Storm of the Century" of March 1993, J. Atmos. Oceanic Technol., 13(1), 198-230.

City of New York (2013), A Stronger, More Resilient New York, 445 pp., New York.

Coch, N. K. (1994), Hurricane hazards along the northeastern Atlantic Coast of the United States, J. Coastal Res., 115-147.

Colle, B. A., F. Buonaiuto, M. J. Bowman, R. E. Wilson, R. Flood, R. Hunter, A. Mintz, and D. Hill (2008), New York City's vulnerability to coastal flooding, Bull. Am. Meteorol. Soc., 89(6), 829-841.

Colle, B. A., K. Rojowsky, and F. Buonaito (2010), New York City storm surges: Climatology and an analysis of the wind and cyclone evolution, J. Appl. Meteorol. Climatol., 49(1), 85-100.

Colle, B. A., M. J. Bowman, K. J. Roberts, M. H. Bowman, C. N. Flagg, J. Kuang, Y. Weng, E. B. Munsell, and F. Zhang (2015), Exploring water level sensitivity for metropolitan New York during Sandy (2012) using ensemble storm surge simulations, J. Mar. Sci. Eng., 3(2), 428-443.

Condon, A. J., and Y. P. Sheng (2012), Optimal storm generation for evaluation of the storm surge inundation threat, Ocean Eng., 43, $13-22$.

Cox, A., J. Greenwood, V. Cardone, and V. Swail (1995), An interactive objective kinematic analysis system, paper presented at Fourth International Workshop on Wave Hindcasting and Forecasting, pp. 171-178, Environment Canada, Ontario, Canada.

Demuth, J. L., M. DeMaria, and J. A. Knaff (2006), Improvement of advanced microwave sounding unit tropical cyclone intensity and size estimation algorithms, J. Appl. Meteorol. Climatol., 45(11), 1573-1581.

Dolan, R., and R. E. Davis (1992), An intensity scale for Atlantic coast northeast storms, J. Coastal Res., 8(4), 840-853.

Donelan, M. (1977), A Simple Numerical Model for Wave and Wind Stress Prediction, 28 pp., Natl. Water Res. Inst., Burlington, Ont., Canada.

Donnelly, J. P., S. Roll, M. Wengren, J. Butler, R. Lederer, and T. Webb (2001), Sedimentary evidence of intense hurricane strikes from New Jersey, Geology, 29(7), 615-618.

Elsner, J. B. (2006), Historical Hurricane Information Tool (HHIT). [Available at http://myweb.fsu.edu/jelsner/temp/HHITProject/hhithome. htm.]

Emanuel, K. (2000), A statistical analysis of tropical cyclone intensity, Mon. Weather Rev., 128(4), 1139-1152.

Espy (1839), Facts collected by Mr. Espy, taken from Newspapers of the time, J. Franklin Inst., 23, 156-158.

FEMA (2014a), Region II Storm Surge Project-Development of Wind and Pressure Forcing in Tropical and Extra-Tropical Storms, 62 pp., Washington, D. C.

FEMA (2014b), Region II Coastal Storm Surge Study: Overview, 15 pp., Washington, D. C.

FEMA (2014c), Region II Storm Surge Project-Joint Probability Analysis of Hurricane and Extratropical Flood Hazards, 95 pp., Washington, D. C. Galarneau, T. J., C. A. Davis, and M. A. Shapiro (2013), Intensification of Hurricane Sandy (2012) through extratropical warm core seclusion, Mon. Weather Rev., 141(12), 4296-4321.

Garratt, J. (1977), Review of drag coefficients over oceans and continents, Mon. Weather Rev., 105(7), 915-929.

Georgas, N. (2010), Establishing Confidence in Marine Forecast Systems: The Design of a High Fidelity Marine Forecast Model for the NY/NJ Harbor Estuary and Its Adjoining Coastal Waters, 272 pp., PhD dissertation, Stevens Institute of Technology, Hoboken, N. J.

Georgas, N., and A. F. Blumberg (2009), Establishing confidence in marine forecast systems: The design and skill assessment of the New York Harbor Observation and Prediction System, Version 3 (NYHOPS v3), paper presented at Eleventh International Conference in Estuarine and Coastal Modeling (ECM11), American Society of Civil Engineers, Seattle, Wash., 4-6 Nov.

Georgas, N., A. Blumberg, and T. Herrington (2007), An operational coastal wave forecasting model for New Jersey and Long Island waters, Shore Beach, 75(2), 30-35.

Georgas, N., P. Orton, A. Blumberg, L. Cohen, D. Zarrilli, and L. Yin (2014), The impact of tidal phase on Hurricane Sandy's flooding around New York City and Long Island Sound, J. Extreme Events, 1, 1450006, doi:10.1142/S2345737614500067.

Grant, W. D., and O. S. Madsen (1979), Combined wave and current interaction with a rough bottom, J. Geophys. Res., 84(C4), $1797-1808$.

Hall, T., and S. Jewson (2007), Statistical modelling of North Atlantic tropical cyclone tracks, Tellus, Ser. A, 59(4), 486-498.

Hall, T., and E. Yonekura (2013), North American tropical cyclone landfall and SST: A statistical model study, J. Clim., 26(21), 8422-8439.

Hall, T. M., and A. H. Sobel (2013), On the impact angle of Hurricane Sandy's New Jersey landfall, Geophys. Res. Lett., 40, 2312-2315, doi: $10.1002 / g r l .50395$. 
Harper, B., J. Kepert, and J. Ginger (2010), Guidelines for converting between various wind averaging periods in tropical cyclone conditions, TCP Sub-Proj. Rep. WMO/TD(1555), World Meteorological Organization, Geneva, Switzerland.

Holland, G. J. (1980), An analytic model of the wind and pressure profiles in hurricanes, Mon. Weather. Rev., 108(8), $1212-1218$.

Holthuijsen, L. H., M. D. Powell, and J. D. Pietrzak (2012), Wind and waves in extreme hurricanes, J. Geophys. Res., 117, C09003, doi:10.1029/ 2012JC007983.

Horsburgh, K., and C. Wilson (2007), Tide-surge interaction and its role in the distribution of surge residuals in the North Sea, J. Geophys. Res., 112, C08003, doi:10.1029/2006JC004033.

Jelesnianski, C., J. Chen, W. Shaffer, U.S. Department of Commerce, National Oceanic and Atmospheric Administration, and National Weather Service (1992), SLOSH: Sea, Lake, and Overland Surges From Hurricanes, Silver Spring, Md.

Kemp, A. C., and B. P. Horton (2013), Contribution of relative sea-level rise to historical hurricane flooding in New York City, J. Quat. Sci., 28(6), 537-541.

Kussman, A. S. (1957), Report on the Hurricane of September 3, 1821, 54 pp., U.S. Weather Bur., New York.

Landsea, C. W., C. Anderson, N. Charles, G. Clark, J. Dunion, J. Fernandez-Partagas, P. Hungerford, C. Neumann, and M. Zimmer (2004), The Atlantic hurricane database re-analysis project: Documentation for the 1851-1910 alterations and additions to the HURDAT database, in Hurricanes and Typhoons: Past, Present and Future, edited by R. J. Murnane and K.-B. Liu, pp. 177-221, Columbia University Press, New York.

Large, W. G., and S. Pond (1981), Open ocean momentum flux measurements in moderate to strong winds, J. Phys. Oceanogr., 11, 324-336.

Lin, N., and D. Chavas (2012), On hurricane parametric wind and applications in storm surge modeling, J. Geophys. Res., 117, D09120, doi: 10.1029/2011JD017126.

Lin, N., K. Emanuel, J. Smith, and E. Vanmarcke (2010), Risk assessment of hurricane storm surge for New York City, J. Geophys. Res, 115, D18121, doi:10.1029/2009JD013630.

Lin, N., K. Emanuel, M. Oppenheimer, and E. Vanmarcke (2012), Physically based assessment of hurricane surge threat under climate change, Nat. Clim. Change, 2(6), 462-467.

Lin, N., P. Lane, K. A. Emanuel, R. M. Sullivan, and J. P. Donnelly (2014), Heightened hurricane surge risk in northwest Florida revealed from climatological-hydrodynamic modeling and paleorecord reconstruction, J. Geophys. Res. Atmos., 119, 8606-8623, doi:10.1002/2014JD021584

Lin, N. R. Kopp, B. Horton, and J. Donnelly (2016), How Does Hurricane Sandy's Flood Frequency Change from 1800 to 2100 ? Proceedings of the National Academy of Sciences, 113(43), 12071-12075, doi: 10.1073/pnas.1604386113.

Lopeman, M., G. Deodatis, and G. Franco (2015), Extreme storm surge hazard estimation in lower Manhattan, Nat. Hazards, $78(1), 1-37$. Ludlum, D. M. W. (1963), Early American Hurricanes, 1492-1870, Am. Meteorol. Soc., Boston, Mass.

Mukai, A., J. Westerink, R. Luettich Jr., and D. Mark (2002), Eastcoast 2001, a tidal constituent database for western North Atlantic, Gulf of Mexico, and Caribbean Sea, Engineer Research and Development Center, Coastal and Hydraulics Laboratory, 196 pp., Vicksburg, Miss.

Niedoroda, A., D. Resio, G. Toro, D. Divoky, H. Das, and C. Reed (2010), Analysis of the coastal Mississippi storm surge hazard, Ocean Eng., $37(1), 82-90$.

NOAA (2015), Tides and Currents. [Available online: https://tidesandcurrents.noaa.gov/.]

NOAA-NHC-HRD (2015), Atlantic Hurricane Best Track (HURDAT), U.S. Natl. Oceanic and Atmos. Admin., National Hurricane Center, Hurricane Research Division. [Available online: http://www.aoml.noaa.gov/hrd/hurdat/Data_Storm.html.]

Orff, K., et al. (2014), Living Breakwaters: Volume II Staten Island and Raritan Bay, 118 pp., Report for the Housing and Urban Dev., competition Rebuild By Design, Scape / Landscape Architecture PLLC, New York.

Orton, P., N. Georgas, A. Blumberg, and J. Pullen (2012), Detailed modeling of recent severe storm tides in estuaries of the New York City region, J. Geophys. Res., 117, C09030, doi:10.1029/2012JC008220.

Orton, P., S. Vinogradov, N. Georgas, A. Blumberg, N. Lin, V. Gornitz, C. Little, K. Jacob, and R. Horton (2015a), New York City Panel on Climate Change 2015 report chapter 4: Dynamic coastal flood modeling, Ann. N. Y. Acad. Sci., 1336(1), 56-66.

Orton, P. M., S. A. Talke, D. A. Jay, L. Yin, A. F. Blumberg, N. Georgas, H. Zhao, H. J. Roberts, and K. MacManus (2015b), Channel shallowing as mitigation of coastal flooding, J. Mar. Sci. Eng., 3(3), 654-673, doi:10.3390/jmse3030654.

Phadke, A. C., C. D. Martino, K. F. Cheung, and S. H. Houston (2003), Modeling of tropical cyclone winds and waves for emergency management, Ocean Eng., 30(4), 553-578.

Pickands, J. (1975), Statistical inference using extreme order statistics, Ann. Stat., 3(1), 119-131.

Powell, M. D., P. J. Vickery, and T. A. Reinhold (2003), Reduced drag coefficient for high wind speeds in tropical cyclones, Nature, 422(6929), $279-283$.

Pugh, D. T. (1987), Tides, Surges and Mean Sea-Level, 487 pp., John Wiley, New York.

Redfield, W. (1831), Remarks on the prevailing storms of the Atlantic coast of the North American States, Am. J. Sci. Arts, $20,17-51$.

Reichl, B. G., T. Hara, and I. Ginis (2014), Sea state dependence of the wind stress over the ocean under hurricane winds, J. Geophys. Res., 119, 30-51, doi:10.1002/2013JC009289.

Resio, D. T., and J. J. Westerink (2008), Modeling the physics of storm surges, Phys. Today, 61, 33-38.

Scileppi, E., and J. P. Donnelly (2007), Sedimentary evidence of hurricane strikes in western Long Island, New York, Geochem. Geophys. Geosyst., 8, Q06011, doi:10.1029/2006GC001463.

Shalowitz, A. L. (1964), Shore and Sea Boundaries, with Special Reference to the Interpretation and use of Coast and Geodetic Survey Data, vol. 2, Interpretation and Use of Coast and Geodetic Survey Data, U.S. Gov. Print. Off., Washington, D. C.

Signell, R., R. Beardsley, H. Graber, and A. Capotondi (1990), Effect of wave-current interaction on wind-driven circulation in narrow, shallow embayments, J. Geophys. Res., 95(C6), 9671-9678.

Sweet, W., C. Zervas, S. Gill, and J. Park (2013), Section 6: Hurricane Sandy inundation probabilities today and tomorrow, in Explaining Extreme Events of 2012 from a Climate Perspective, Bull. Amer. Meteorol. Soc., 94(9), S17-S20.

Swiss Re (2014), The Big One: The East Coast's USD 100 Billion Hurricane Event, 21 pp., Armonk, New York.

Talke, S., P. Orton, and D. Jay (2014), Increasing storm tides at New York City, 1844-2013, Geophys. Res. Lett., 41, 3149-3155, doi:10.1002/ 2014 GL059574.

Tang, Y. M., B. Sanderson, G. Holland, and R. Grimshaw (1996), A numerical study of storm surges and tides, with application to the North Queensland coast, J. Phys. Oceanogr., 26(12), 2700-2711.

Taylor, P. K., and M. J. Yelland (2001), The dependence of sea surface roughness on the height and steepness of the waves, J. Phys. Oceanogr., 31(2), 572-590.

Toro, G., A. Niedoroda, C. Reed, and D. Divoky (2010), Quadrature-based approach for the efficient evaluation of surge hazard, Ocean Eng., $37(1), 114-124$. 
USACE (2015), North Atlantic Coast Comprehensive Study: Resilient Adaptation to Increasing Risk: Main Report, 140 pp., U.S. Army Corps of Eng.

Vecchi, G. A., and T. R. Knutson (2011), Estimating annual numbers of Atlantic hurricanes missing from the HURDAT database (1878-1965) using ship track density, J. Clim., 24(6), 1736-1746.

Vickery, P., P. Skerlj, and L. Twisdale (2000), Simulation of hurricane risk in the US using empirical track model, J. Struct. Eng., 126(10), 12221237.

Wang, H. V., J. D. Loftis, Z. Liu, D. Forrest, and J. Zhang (2014), The storm surge and sub-grid inundation modeling in New York City during Hurricane Sandy, J. Mar. Sci. Eng., 2(1), 226-246.

Zervas, C. (2013), Extreme water levels of the United States 1893-2010, NOAA Tech. Rep. NOS CO-OPS 067, 200 pp., NOAA Natl. Ocean Serv. Cent. for Oper. Oceanogr. Products and Serv., Silver Spring, Md. 